\title{
Review Article \\ Regulation of ROS Production and Vascular Function by Carbon Monoxide
}

\author{
Yoon Kyung Choi, ${ }^{1}$ Elaine D. Por, ${ }^{2}$ Young-Guen Kwon, ${ }^{3}$ and Young-Myeong Kim ${ }^{1}$ \\ ${ }^{1}$ Vascular Homeostasis Laboratory, Department of Molecular and Cellular Biochemistry, School of Medicine, \\ Kangwon National University, Chuncheon, Gangwon-do 200-701, Republic of Korea \\ ${ }^{2}$ Department of Pharmacology, School of Medicine, University of Texas Health Science Center, San Antonio, TX 78229, USA \\ ${ }^{3}$ Department of Biochemistry, College of Life Science and Biotechnology, Yonsei University, Seoul 120-749, Republic of Korea
}

Correspondence should be addressed to Young-Myeong Kim, ymkim@kangwon.ac.kr

Received 13 April 2012; Accepted 4 July 2012

Academic Editor: Michael Everton Andrades

Copyright (C) 2012 Yoon Kyung Choi et al. This is an open access article distributed under the Creative Commons Attribution License, which permits unrestricted use, distribution, and reproduction in any medium, provided the original work is properly cited.

Carbon monoxide $(\mathrm{CO})$ is a gaseous molecule produced from heme by heme oxygenase (HO). CO interacts with reduced iron of heme-containing proteins, leading to its involvement in various cellular events via its production of mitochondrial reactive oxygen species (ROS). CO-mediated ROS production initiates intracellular signal events, which regulate the expression of adaptive genes implicated in oxidative stress and functions as signaling molecule for promoting vascular functions, including angiogenesis and mitochondrial biogenesis. Therefore, $\mathrm{CO}$ generated either by exogenous delivery or by HO activity can be fundamentally involved in regulating mitochondria-mediated redox cascades for adaptive gene expression and improving blood circulation (i.e., $\mathrm{O}_{2}$ delivery) via neovascularization, leading to the regulation of mitochondrial energy metabolism. This paper will highlight the biological effects of CO on ROS generation and cellular redox changes involved in mitochondrial metabolism and angiogenesis. Moreover, cellular mechanisms by which CO is exploited for disease prevention and therapeutic applications will also be discussed.

\section{Overview}

Similar to nitric oxide (NO), produced by a family of nitric oxide synthase (NOS), $\mathrm{CO}$ is also endogenously generated from heme by the catalytic reaction of HO. To date, three isoforms of $\mathrm{HO}$ (e.g., HO-1, HO-2 and HO-3) have been identified [1]. The isoforms are produced by different genes and show different tissue distributions and molecular properties. HO-1, first identified as a stress protein (32$\mathrm{kDa}$ ), may be induced in response to a broad spectrum of stimuli, including oxidants, heavy metals, $\mathrm{NO}$, and immune stimulants $[2,3]$. The second isoform $\mathrm{HO}-2$, a $36-\mathrm{kDa}$ protein, is constitutively expressed and present in high levels in the brain and testes [4]. Although not expressed in humans, the third isoform identified, HO-3 (33-kDa), is highly homologous to $\mathrm{HO}-2$ but possesses significantly lower catalytic activity. $\mathrm{HO}-3$ is considered as a pseudogene derived from HO-2. HO proteins can be localized in several subcellular compartments. Rat liver $\mathrm{HO}$ was first identified to be integrated into microsomes by embedding its Cterminal portion into membranes $[5,6]$. $\mathrm{HO}-1$ and $\mathrm{HO}-2$ were also found in the endoplasmic reticulum (ER) with an insertion sequence at the $\mathrm{C}$-terminal region, while the rest of the protein is cytoplasmic [7-9]. $\mathrm{HO}-1$ can be proteolytically cleaved from the ER and translocated to the nucleus after exposure to hemin or hypoxia, and this localization is linked to the transcriptional upregulation of cytoprotective genes [10]. HO-1 can also be translocated into mitochondria and is attributed as a novel cytoprotective mechanism against mitochondrial oxidative stress [11]. Interestingly, $\mathrm{HO}-1$ is localized in plasma membrane caveolae when endothelial cells were exposed to stimuli, such as hemin, LPS, or hypoxia, in which caveolin-1 interacts with and modulates HO1 activity [12], suggesting that caveolin-1 may act as an important regulatory molecule in CO-mediated signaling in endothelial cells. In the human body, both HO-1 and HO-2 catalyze three successive monooxygenation steps to convert intracellular heme to CO, biliverdin, and free iron 
(Figure 1(a)). Biliverdin is subsequently metabolized to bilirubin by biliverdin reductase, and the free iron induces ferritin synthesis. Thus, the predominant endogenous source of $\mathrm{CO}$ arises from oxidative degradation of heme by $\mathrm{HO}$ (Figure 1(a)). Although the majority of heme is derived from senescing red blood cells and ineffective erythropoiesis, a small fraction arises from the degradation of other heme proteins, such as myoglobin, catalase, peroxidases, and cytochromes [13]. Under pathological conditions, additional $\mathrm{CO}$ is produced via lipid peroxidation [14] and the metabolic activity of intestinal bacteria [15].

To adapt to challenges by unfavorable environmental conditions, living cells have evolved networks of different responses that control diverse forms of stimuli. One of the key adaptive responses is Nrf2-mediated transcriptional upregulation of HO-1. $\mathrm{CO}$ production by HO-1 not only influences $\mathrm{O}_{2}$ consumption during mitochondrial respiration by acting as a reversible inhibitor of cytochrome $c$ oxidase in the electron transfer chain and as a guardian of cellular energy homeostasis, but also enhances $\mathrm{O}_{2}$ delivery by stimulating angiogenesis [16]. Moreover, $\mathrm{CO}$ produces superoxide and $\mathrm{H}_{2} \mathrm{O}_{2}$ from mitochondrial complex III by binding to cytochrome $a, a_{3}$ (complex IV) of the electron transport chain, thus, triggering the activation of redoxsensitive signaling pathways for cytoprotection and energy balance. Therefore, $\mathrm{CO}$ is increasingly accepted as a cytoprotective and homeostatic molecule with important signaling capabilities in physiological and pathological situations.

It has been proposed that cytoprotective roles of the HO-1/CO system are initiated by a series of molecular reactions or interactions, or both in response to changes in redox states of the cell [13]. The earliest event in cells and tissues exposed to a low concentration of $\mathrm{CO}$ is the rapid production of ROS (i.e., superoxide, $\mathrm{H}_{2} \mathrm{O}_{2}$, and hydroxyl radical). Accumulating evidence suggests that endogenous ROS stimulates cell proliferation, migration and tube formation, which are typical properties of angiogenesis. Moreover, these angiogenic effects can be regulated by endogenous antioxidant enzymes such as superoxide dismutase (SOD) and thioredoxin [17]. It is known that ROS modulates new blood vessel formation via regulation of various angiogenic factors such as hypoxia-inducible factor (HIF)- $1 \alpha$ and vascular endothelial growth factor (VEGF) [18]. As described above, $\mathrm{CO}$ can promote ROS production from mitochondria by inhibiting complex IV. These results suggest that CO can stimulate angiogenesis by elevating intracellular ROS levels. In addition, $\mathrm{CO}$ synthesized from the catalytic reaction of HO- 1 induces the production of proangiogenic factors, such as VEGF, interleukin (IL)-8, and stromal-derived factor (SDF)-1 and decreases antiangiogenic mediators such as soluble VEGF receptor-1 (sFlt-1) and soluble endoglin (sEng). Consequently, these events lead to the promotion of endothelial cell proliferation, migration, and antiapoptotic responses [19-21]. In addition to $\mathrm{CO}$, other endogenous products can play an obligatory role in $\mathrm{HO}$-mediated regulation of vascular function, including angiogenesis. Biliverdin stimulates the induction of proangiogenic factors, such as VEGF and IL-8 in human keratinocytes [22]. Although, ferrous iron has not been shown to induce protein levels of
HIF- $1 \alpha$ and VEGF, this metal ion increases the synthesis of ferritin synthesis, which promotes angiogenesis by inhibiting the antiangiogenic activity of cleaved high-molecular-weight kininogen (HKa) [23] (Figure 1(b)).

Cells require $\mathrm{O}_{2}$ for energy metabolism, and modulators of mitochondrial oxidative metabolism can stimulate the supply of $\mathrm{O}_{2}$ and nutrients by improving blood circulation via angiogenesis. $\mathrm{CO}$ stimulates angiogenesis via production of intracellular ROS and angiogenic factors, but also stimulates mitochondrial biogenesis via induction of metabolic modulators such as peroxisome-proliferatoractivated receptor- $\gamma$ (PPAR- $\gamma$ ) and PPAR- $\gamma$ coactivator$1 \alpha(\mathrm{PGC}-1 \alpha)$ [24, 25]. Inhibition of CO-induced ROS by antioxidant enzymes (SOD and catalase), antimycin A (an inhibitor of complex III of the electron transport chain), or other antioxidants abrogates CO-induced PPAR- $\gamma$ expression [24]. In addition, CO elicits a mild oxidative stress response that stimulates mitochondrial energy metabolism, PGC- $1 \alpha$ protein expression, and mitochondrial DNA copy number [26]. These observations support the idea that CO ameliorates cellular energetics and stimulates mitochondrial biogenesis via a modest mitochondrial oxidative stress.

The HO-1/CO system has received considerable attention as a target for the development of effective therapeutic interventions against mitochondrial energy metabolism and degenerative vascular diseases, which are directly associated with cellular ROS generation. This paper will highlight the biological effects of $\mathrm{CO}$ on energy metabolism and angiogenesis in terms of redox states and discuss mechanisms by which this gas is currently exploited for disease prevention and therapeutic applications.

\section{Physiological Significance of $\mathrm{CO}$ on Redox Control}

Proximal targets for $\mathrm{CO}$ include those on or near the cellular surface, such as soluble guanylyl cyclase (sGC), hemecontaining potassium channels, NOS, and NADPH oxidase (Nox). More distal cellular targets include mitochondria and heme-containing transcription factors such as BACH1 or NPAS2. Although CO can activate sGC to produce the cellular second messenger cGMP [27], it predominantly inhibits the activity of hemeproteins, such as Nox, to modulate the production of superoxide in tumor-necrosis-factor-(TNF-) $\alpha$-stimulated endothelial cells (ECs) [28]. CO is known to inhibit $\mathrm{O}_{2}$ consumption by inhibiting mitochondrial cytochrome c oxidase (COX), which is a terminal electron acceptor of the electron transport chain $[29,30]$. Inhibition of COX by $\mathrm{CO}$ suppresses oxidative phosphorylation and reduces ATP production. Simultaneously, suppression of oxidative phosphorylation alters the redox state of the electron transport chain and produces ROS (e.g., superoxide and $\mathrm{H}_{2} \mathrm{O}_{2}$ ). Although superoxide and $\mathrm{H}_{2} \mathrm{O}_{2}$ are generally considered to be toxic byproducts of respiration, recent evidence suggests that ROS is an important modulator of eukaryotic signal transduction regulating biological processes as diverse as adaptation for oxidative stress, immune activation, and vascular remodeling in mammals $[13,31]$. 


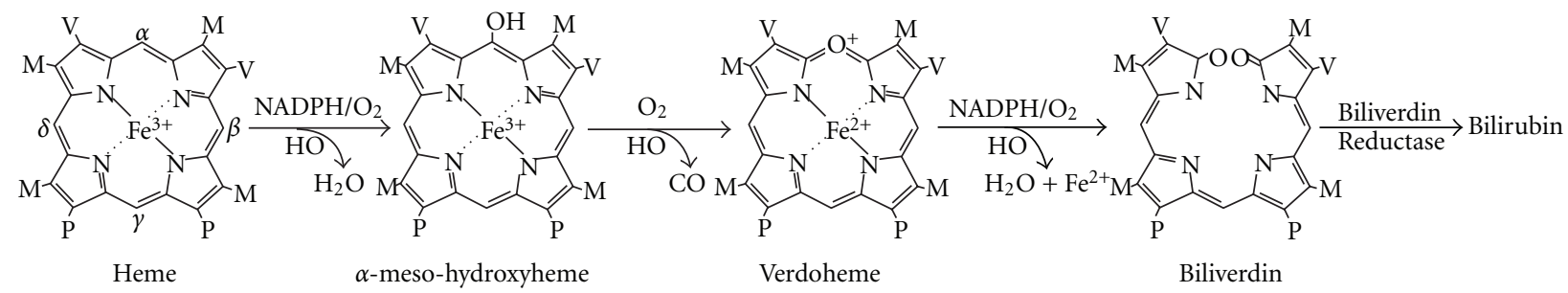

(a)

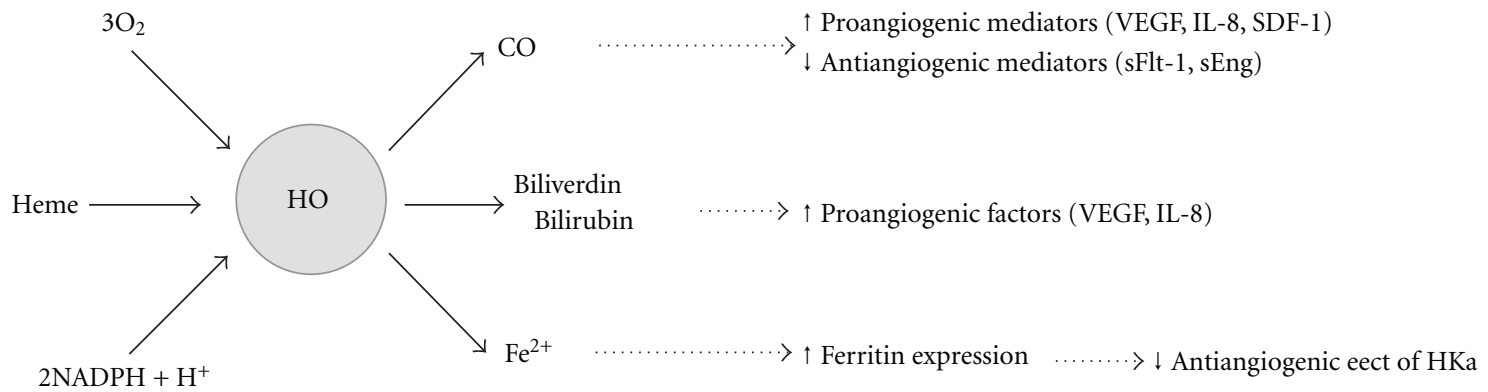

(b)

FIGURE 1: The heme degradation pathway and roles of its byproducts in the production of angiogenic modulators. (a) Reaction intermediates in the heme oxygenase-catalyzed oxidation of heme to biliverdin. The substituents on porphyrin are vinyl (V), methyl (M), and propionate (P). The $\alpha-, \beta-, \gamma$-, and $\delta$-meso positions are labeled. The HO reaction consists of three oxidation steps and initiates with the formation of the $\mathrm{Fe}^{3+}$ heme-HO complex. Next, $\mathrm{Fe}^{3+}$ heme is reduced to the $\mathrm{Fe}^{2+}$ state by the electron donated from NADPH, and this step produces $\mathrm{CO}$ by the region-specific cleavage of the porphyrin ring of heme at the $\alpha$-meso carbon atom. The final step is $\mathrm{O}_{2}$ binding to verdoheme, which produces $\mathrm{Fe}^{2+}$ and biliverdin. Biliverdin is converted by biliverdin reductase to bilirubin. (b) Potential proangiogenic effects of heme-degraded products such as $\mathrm{CO}$, biliverdin/bilirubin and $\mathrm{Fe}^{2+}$. These products possess potential proangiogenic effects by inducing proangiogenic mediators or by antagonizing antiangiogenic factors.

$\mathrm{O}_{2}$-sensing enzyme systems in ECs, including COX, NADPH oxidase, and endothelial nitric oxide synthase (eNOS) are important targets of ROS generation in vessels (Figure 2).

\subsection{Effects of $\mathrm{CO}$ on Mitochondrial ROS. ROS induced by} $\mathrm{HO}-1$-mediated $\mathrm{CO}$ production could be predominantly generated from mitochondria via inhibition of COX activity. Mitochondrial ROS production is modulated largely by the rate of electron flow through respiratory chain complexes. Mitochondria contain three classes of cytochromes, denoted $a, b$, and $c$, which are potential CO targets. CO binds to the reduced heme iron of COX, with a Ki value of $0.3 \mu \mathrm{M}$, resulting in the formation of cytochrome $a, a_{3}$-CO complex, and its binding to COX is reversible and competitive with $\mathrm{O}_{2}$. $\mathrm{CO}$ derived from $\mathrm{HO}-1$ inhibits mitochondrial respiration by $12 \%$ under $20 \% \mathrm{O}_{2}$, but by $70 \%$ under $1 \% \mathrm{O}_{2}$ (reviewed in [13]). The primary effect of $\mathrm{CO}$ on mitochondria is to retard the rate of electron transport, thus enabling electrons to accumulate in the cytochrome $b c 1$ region of complex III in the electron chain. In turn, electrons can be donated to molecular oxygen to generate superoxide and thereby increase the amount of the ROS oxidants in the cell to drive subsequent cellular redox signaling events (reviewed in [32]) (Figure 2).

Cells exposed to CO increase ROS generation, which is inhibited by antimycin A [33] and depletion of mitochondria [21], further confirming the implication of mitochondria as the source of CO-mediated ROS production. It has been also demonstrated that endogenous $\mathrm{CO}$ increases the reduction state of cytochrome $b c l$ of the respiratory chain in an animal model [25]. Treatment with exogenous CO-releasing compound CORM-2 stimulates platelet-derived-growthfactor-(PDGF-) induced ROS generation and inhibits vascular smooth muscle cell (VSMC) proliferation, which are reversed by the antioxidant $N$-acetylcysteine [34]. Authentic $\mathrm{CO}$ gas protects against lung ischemia-reperfusion injury via an increase in the activity of antioxidant enzymes such as MnSOD (SOD2) and glutathione by mitochondrial ROS generation [21]. These results implicate $\mathrm{CO}$ in physiological and pathological consequences of mitochondria-dependent ROS generation and redox signal cascades. Furthermore, regulation of mitochondrial function is critical for the control of oxidative stress and regulation of gene expression, especially in view of the fact that $\mathrm{HO}-1$-deficient individuals are afflicted with excessive and persistent oxidant-mediated damage $[35,36]$. These observations suggest that CO regulates mitochondrial function to generate ROS, which is responsible for controlling cellular redox states and adaptive responses for oxidative stress.

2.2. Effects of CO on NADPH Oxidase. $\mathrm{CO}$ can also regulate ROS generation from cytoplasmic membrane-bound hemoproteins, including NADPH oxidase. In phagocytic cells, NADPH oxidases consist of membrane-bound cytochrome $b_{558}$, comprising the catalytic gp91 $91^{\text {phox }}$ and the $\mathrm{p} 22^{\text {phox }}$ subunits, cytosolic regulatory components including $\mathrm{p} 47^{\text {phox }}$, 


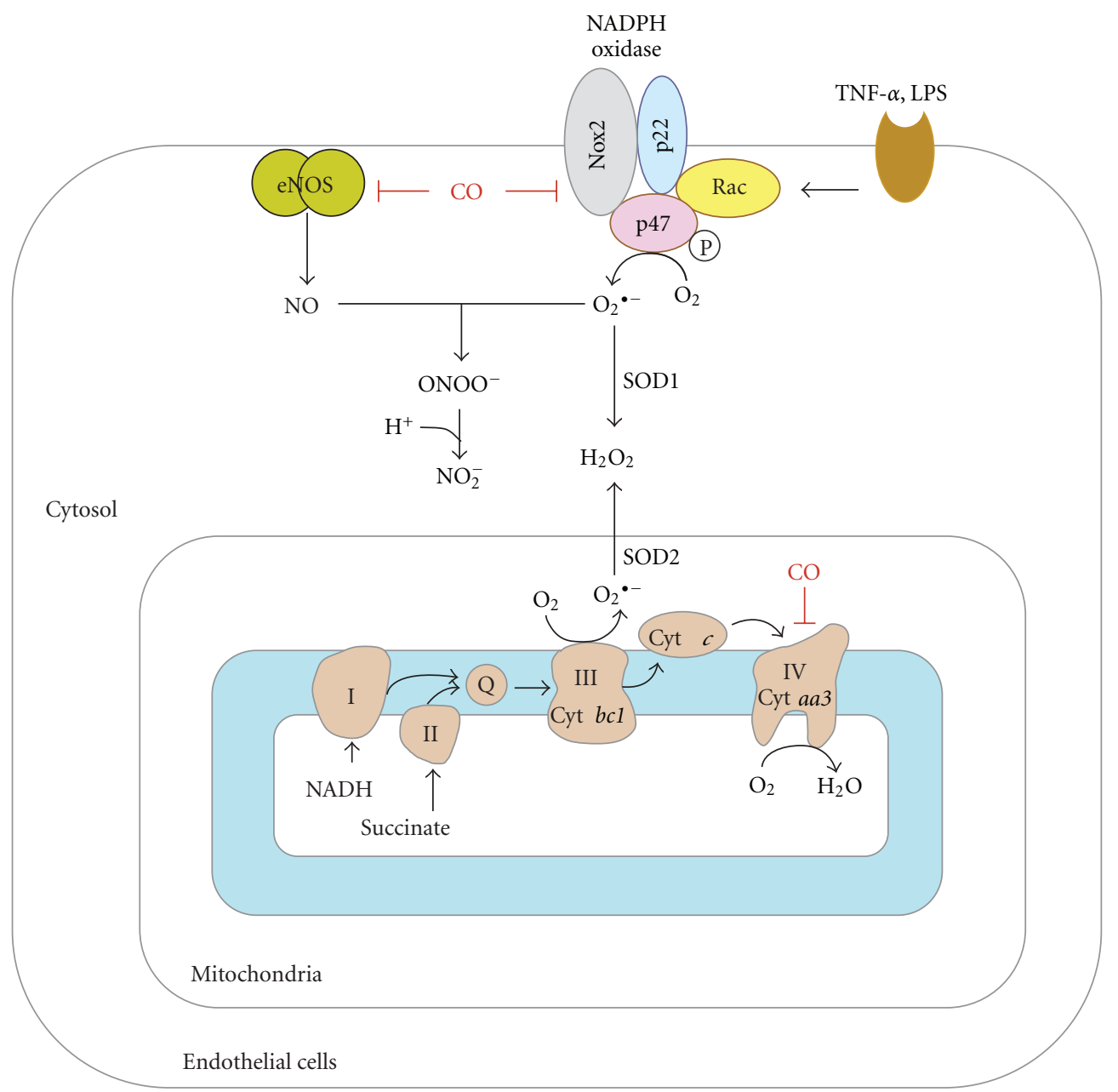

FIGURE 2: Effects of CO on targets of ROS generation in endothelial cells. CO binds to cytochrome c oxidase (COX), which is a terminal electron acceptor (complex IV) of the electron transport chain, which changes the redox state of the electron transport chain and produces ROS in mitochondria. CO-dependent mitochondrial superoxide is converted to $\mathrm{H}_{2} \mathrm{O}_{2}$ by SOD2 (Mn-SOD). Stimulation with TNF- $\alpha$ and LPS induces the recruitment of Nox $2, \mathrm{p} 47^{\text {phox }}$, and Rac1 into lipid rafts, thereby promoting Nox activation and ROS production. Superoxide interacts with eNOS-derived NO to produce peroxynitrite, which contributes to endothelial dysfunction. Binding of CO to the heme moiety of Nox and eNOS inhibits production of superoxide and NO, respectively.

p67 ${ }^{\text {phox }}$, and the small Rho GTPase Rac1 (reviewed in [37]). Several homologues along with gp91 ${ }^{\text {phox }}$ (also termed Nox2) are designated the Nox family of NADPH oxidases to include Nox1 to Nox5, Duox1 and Duox2, which differ in catalytic activity, response to stimuli, and type of ROS released [38]. The NADPH oxidase isoforms Nox1, Nox3, Nox4, Nox5 (only human), and Duox1/2 are expressed in nonphagocytic cells. Nox1, Nox2, Nox4, and Nox5 (only human) are expressed in ECs, whereas Nox2 and Nox4 are found in stem/progenitor cells. ECs express the entire phagocytic NADPH oxidase subunits such as Nox1, Nox2, Nox4, and Nox5, as well as $\mathrm{p} 22^{\text {phox }}$ Rac1, and $\mathrm{p} 47^{\text {phox }}$. These Nox enzymes are major source of ROS generation in ECs stimulated with angiogenic factors, including VEGF and angiopoietin-1. Subsequent increases in cell proliferation and migration suggest that Nox homologues expressed in
EC play an important role in angiogenesis (reviewed in [37]). Binding of CO to the heme moiety of Nox decreases ROS accumulation, and recent reports demonstrate that the protective effects of $\mathrm{CO}$ seen in macrophages, ECs, and VSMCs are attributed to a decrease in ROS generation via inhibition of catalytic activity of activated Nox (reviewed in [32]). The plasma membrane-associated gp91 ${ }^{\text {phox }}$ subunit is a flavohemoprotein containing one FAD and two hemes that catalyze the NADPH-dependent reduction of oxygen to form superoxide in LPS-treated macrophages [39]. The toll-like receptor 4 (TLR4) signaling pathway, responsible for inflammatory gene expression, is negatively regulated by $\mathrm{CO}$ derived from $\mathrm{HO}-1$. $\mathrm{CO}$ functions are to block the translocation of TLR4 to lipid rafts via suppression of Nox-mediated ROS production in LPSstimulated macrophages [39]. Interestingly, CO produced by 
the CO-releasing molecule CORM-A1 and endogenous HO1 induction protects cerebral microvascular ECs from TNF$\alpha$-induced apoptosis by inhibiting Nox4-dependent ROS production [28]. In airway VSMCs, the CO donor CORM-2 decreases VSMC proliferation by inhibiting ERK1/2 MAPK phosphorylation and cyclin D1 expression via suppression of ROS generation from Nox [34]. Therefore, CO can play an important role in various cell functions, such as EC survival, VSMC proliferation, and angiogenesis by decreasing ROS generation via interaction with the heme iron of Nox.

Despite the differential effects of $\mathrm{CO}$ on mitochondria and Nox enzymes, crosstalk between mitochondrial and Nox-induced ROS has been suggested. Recent reports demonstrate that ROS production by hypoxic mitochondria induces Nox1 expression to amplify ROS generation $[40,41]$, thus, resulting in an elevation of cytosolic calcium to induce contraction in pulmonary artery VSMCs [41]. Does COinduced ROS generation in mitochondria influence NADPH oxidase activity, resulting in the amplification of ROS? Lamon et al. [42] demonstrated that both authentic CO and the exogenous CO donor CORM-3 induces vasoconstriction in isolated interlobular arteries via mitochondrial production of superoxide, which is implicated in pathways associated with decreased $\mathrm{NO}$ bioavailability via direct interaction with $\mathrm{NO}$ as well as reduced cGMP production via oxidation of the heme moiety of sGC. These events were reversed by pharmacological inhibitors of multiple oxidases, including NADPH oxidase, resulting in the conversion of function of CO from constrictor to dilator [42]. Similarly, the antioxidants, biliverdin and bilirubin, can inhibit COinduced superoxide production and vasoconstriction, allowing for a vasodilatory response to $\mathrm{CO}$. These results suggest that $\mathrm{CO}$ can regulate vascular relaxation and constriction in a ROS-dependent manner.

2.3. Effects of CO on NOS. NOS, a heme-containing enzyme, predominantly produces not only NO from L-arginine and NADPH, but also superoxide from NADPH in the absence of L-arginine. $\mathrm{NO}$ rapidly reacts with $\mathrm{O}_{2}{ }^{-}$to produce peroxynitrite $\left(\mathrm{ONOO}^{-}\right)$, a highly reactive nitrogen species that might elicit harmful effects to cells and could be removed via glutathione [43]. The contribution of $\mathrm{CO}$ to the regulation of NO is Janus-faced since low levels of CO increase steady-state levels of NO, without altering NOS activity, by competing against heme moieties, which are alternative targets or scavenging molecules for NO [44]. However, higher levels of CO inhibit NO synthase [45], indicating that the relationship between $\mathrm{CO}$ and $\mathrm{NO}$ is complex, dynamic, and adaptable. Thus, a high concentration of CO can inhibit NO synthesis and/or actions, interfering with vasodilatory mechanisms mediated by NO. It suggests that there are several mechanisms by which the $\mathrm{HO} / \mathrm{CO}$ system might modulate NO-dependent biological events (reviewed in [13]). A first feasible mechanism is that $\mathrm{HO}$ can downregulate catalytic activities of hemoproteins, including NOS, via oxidative degradation of heme [46, 47]. A second possibility is related to substrate availability. Since both $\mathrm{HO}$ and NOS enzymes use NADPH as a reducing equivalent and molecular $\mathrm{O}_{2}$ as cosubstrates, both enzyme activities under normal conditions may depend on their competition for these substrates. Thus, both enzymes may regulate each other's activity through reciprocal competition with these substrates. A third potential mechanism is associated with a key observation which indicates that NOS activity is directly inhibited by $\mathrm{CO}$ in vitro [48]. This observation suggests that an inhibitory function of $\mathrm{CO}$ on $\mathrm{NO}$ generation appears to be mediated by $\mathrm{CO}$ binding to the prosthetic heme of NOS (Figure 2). A high concentration of $\mathrm{CO}$, as much as $1 \mathrm{mM}$, should be available to generate this inhibition. However, $\mathrm{CO}$ concentrations in tissues have been reported to be only on the order of $\sim 1 \mu \mathrm{M}$, significantly lower than the required concentration of $\mathrm{CO}$ for the inhibition. Consequently, the reciprocal regulatory mechanism between $\mathrm{HO} / \mathrm{CO}$ pathway and NOS/NO axis in vivo relies on local concentrations of $\mathrm{CO}$, which may be significantly higher than global averages would suggest.

$\mathrm{CO}$ has been shown to function as both a vasoconstrictor and vasodilator. While the majority of data supports a prodilatory role for $\mathrm{CO}$ in the liver where endogenous NO production appears low [49], evidence for vasoconstrictor effects of $\mathrm{CO}$ under sufficient amounts of $\mathrm{NO}$ has also emerged [50]. High levels of $\mathrm{CO}$ can act as a negative regulator of eNOS activity by interacting with its catalytic heme moiety in ECs, leading to suppression of NO production and elevation of vasoconstriction $[45,51]$. Specific overexpression of HO-1 in VSMCs exhibits systemic hypertension through attenuation of NO-induced vasodilation [50]. Lamon et al. [42] showed that inhibition of NOS with L-NAME reduces CO-induced elevation in superoxide levels, consequently inducing vasodilation. Since ROS is implicated in pathways associated with direct vasoconstriction as well as impairment of vasodilation, CO produced in the vasculature may promote vasoconstriction in a ROS-dependent manner. The result showing that antioxidants can convert a role of CO from a vasoconstrictor to vasodilator role [42] supports this idea.

Although CO can function as vasoconstrictor, as described above, exogenous $\mathrm{CO}$ was first shown to dilate rat coronary arteries and proposed to act in a manner similar to $\mathrm{NO}$, that is, via activation of sGC to produce cGMP $[52,53]$. Although CO binds sGC with 30-100-fold less potency than $\mathrm{NO}$, this gas is able to efficiently activate sGC in physiological settings. Apparent discrepancy, as to whether or not CO functions as a vasodilator or vasoconstrictor, is thought to depend on intracellular redox potential of vascular ECs exposed to CO. There are two potential regulatory systems for controlling vascular tone in CO-exposed endothelium, which simultaneously produce both CO-mediated ROS and eNOS-dependent NO. Firstly, ECs containing high levels of redox potential decrease intracellular levels of ROS, particularly superoxide as a $\mathrm{NO}$ scavenger and increase cGMP production from sGC by $\mathrm{NO}$ and $\mathrm{CO}$, leading to promotion of vasorelaxation. Secondly, cells with low antioxidant levels lead to an increase in intracellular ROS accumulation and a decrease in NO bioavailability, allowing for vasoconstriction. Therefore, differential effects of CO on the regulation of vascular tone depend on intracellular 
levels of ROS from mitochondria and Nox. Furthermore, mitochondrial ROS generated by $\mathrm{CO}$ can be involved in the activation of other oxidases, further increasing intracellular ROS level and redox-mediated signaling pathways. Therefore, vasoregulatory mechanisms associated with $\mathrm{CO}$ rely on the relationship between $\mathrm{CO}$ and ROS generation.

$\mathrm{NO}$ and related reactive nitrogen species are among the most potent inducers of the HO-1 gene [54]. NO applied as a gas or released from chemical donor compounds markedly induces $\mathrm{HO}-1$ activity through transcriptional and posttranscriptional regulation [54], resulting in COmediated cytoprotective effects. Interestingly, exposure of hepatocytes to exogenous $\mathrm{CO}$ resulted in a rapid induction of iNOS expression via nuclear factor- $\kappa \mathrm{B}(\mathrm{NF}-\kappa \mathrm{B})$ activation and a subsequent increase in NO production, which is required for the protective effect of $\mathrm{CO}$. Conversely, the protective effect of $\mathrm{NO}$ is required for $\mathrm{CO}$ production via upregulation of $\mathrm{HO}-1$ expression [55]. These results indicate that both $\mathrm{NOS} / \mathrm{NO}$ and $\mathrm{HO}-1 / \mathrm{CO}$ pathways are involved in protective effects and vascular function via synergistic interaction between these two pathways.

To summarize, although NO acts as a principal vasodilator, NO alone does not solely dominate the control of vascular tone. $\mathrm{CO}$ derived from $\mathrm{HO}-1$ may play dual functions in vasoregulation by activating sGC similar to NO (vasodilation) or by promoting direct inhibition of eNOS activity and ROS generation (vasoconstriction). This differential effect can be generated depending on local concentrations of $\mathrm{CO}$ [56]. In addition, reciprocal crosstalk between $\mathrm{NOS} / \mathrm{NO}$ and $\mathrm{HO}-1 / \mathrm{CO}$ pathways are required for the cytoprotective effect showing an essential synergy between these two molecules in tandem. Organs and cells are specialized in their ability to produce different gases (i.e., $\mathrm{CO}$ and $\mathrm{NO}$ ) and modulate their diverse signals via ROS generation at different rate. As such, this would imply a critical role for $\mathrm{CO}, \mathrm{NO}$, and ROS in maintaining vascular tone as well as cytoprotective activity.

\section{Physiological Significance of CO on Angiogenesis}

Oxygen homeostasis is of critical importance for maintaining the viability of all tissues. Lack of sufficient tissue oxygenation is predominantly caused by impaired blood flow. Hypoxia or ischemia results in the upregulation of HIF- $1 \alpha$, which is an important $\mathrm{O}_{2}$ sensor. HIF- $1 \alpha$ regulates several stages of vessel formation, ranging from EC fate decisions to vasculogenesis and angiogenesis [56]. Recently, we reported that overexpression of HO- 1 stabilizes HIF- $1 \alpha$ protein in astrocytes cells, leading to upregulation of VEGF expression [57]. HIF- $1 \alpha$ can also activate the transcription of SDF-1 (also known as CXCL12) in ECs, resulting in increases in the adhesion, migration, and homing of circulating CXCR4(a cognate receptor for SDF-1) positive progenitor cells to ischemic tissue [58]. Thus, the $\mathrm{HO}-1 / \mathrm{CO}$ pathway promotes angiogenesis by increasing HIF- $1 \alpha$-mediated proangiogenic factors.
Genetic and gene transfer studies have shed light on the distinct roles of HO-1 in angiogenesis. Mice lacking the functional HO-1 gene are embryonically lethal in $>95 \%$ of all fertilizations, suggesting that the $\mathrm{HO}-1 / \mathrm{CO}$ axis may play an important role in prenatal angiogenesis $[35,59]$. In fact, HO-1 knockout mice showed lower basal and $\mathrm{H}_{2} \mathrm{O}_{2}$ induced production of the strong proangiogenic factor VEGF [60]. VEGF can elevate HO-1 expression and activity in ECs and vice versa, and VEGF-induced angiogenesis is inhibited by the HO-1 antagonist [61], suggesting a positive-feedback loop between VEGF and the HO-1/CO pathway for synergistic promotion of angiogenesis. HOderived $\mathrm{CO}$ contributes to angiogenesis by increasing the synthesis of VEGF, HO-1 and SDF-1 and potentiating their effects on ECs [62-64]. CO also induces VEGF synthesis in the EC-surrounding cells such as VSMCs, macrophages, and astrocytes $[22,57,65]$. The systemic effect of $\mathrm{CO}$ on VEGF expression was shown by Marti and Risau [66], who demonstrated that animals kept for $6 \mathrm{~h}$ in an atmosphere containing $0.1 \% \mathrm{CO}$ exhibited significant induction of VEGF and VEGF receptors in various organs. These pieces of evidence implicate a link between HO-1/CO, HIF-1 $\alpha$, VEGF, and SDF-1 for the promotion of angiogenesis.

3.1. HO-1/CO-Induced VEGF Expression via HIF-1 $\alpha$. Angiogenesis is an adaptive response to hypoxia under the master command of HIF. HIF- $1 \alpha$ is a potent inducer of VEGF, and VEGF is a pivotal mediator of vasculogenesis, angiogenesis, and vascular permeability. Mitochondrial ROS may diffuse to the cytosol where it activates a variety of signaling pathways, resulting in divergent biological responses such as the activation of HIF- $\alpha$. All three isoforms, HIF-1, HIF-2, and HIF-3 are composed of two subunits: HIF- $\alpha$ and HIF- $\beta$. Since the first discovery of HIF-1 in 1992, a variety of $\mathrm{O}_{2}$-sensing genes encoding proteins that mediate cell survival, metabolism, and angiogenesis have been identified to be regulated by HIF-1 $\alpha$ [56]. A critical regulatory mechanism for HIF$1 \alpha$ stability is mainly associated with its rapid ubiquitinmediated proteosomal degradation. In the presence of oxygen, proline hydroxylation of HIF- $1 \alpha$ by prolyl hydroxylase (PHD) activity is a critical step for regulating its protein level. PHD belongs to an $\alpha$-ketoglutarate (2-oxoglutarate)dependent dioxygenase superfamily [67], which uses $\mathrm{O}_{2}$ as a cosubstrate to add a hydroxyl group to specific proline residues at 402 and 564 within the oxygen-dependent degradation domain of HIF-1 $\alpha$ [68] (Figure 3). This enzyme requires $\mathrm{Fe}^{2+}$ to assemble into its active conformation, and the oxidation of $\mathrm{Fe}^{2+}$ to $\mathrm{Fe}^{3+}$ abolishes the catalytic activity of PHD [69]. Therefore, oxidizing agents, including ROS, inhibit PHD activity via oxidation of iron, while reductants or antioxidants, such as ascorbate and cysteine, reduce the $\mathrm{Fe}^{3+}$ back to $\mathrm{Fe}^{2+}$ in order for the enzyme to be recycled $[70,71]$. Therefore, cellular redox potential can affect PHD activity and HIF- $1 \alpha$-dependent VEGF expression (Figure 3 ).

Treatments of cells with exogenous $\mathrm{H}_{2} \mathrm{O}_{2}$ and growth factors, which induce $\mathrm{H}_{2} \mathrm{O}_{2}$ production are sufficient to stabilize HIF-1 $\alpha$ under normoxic condition [71]. The cells deficient in junD, which is responsible for antioxidant gene 


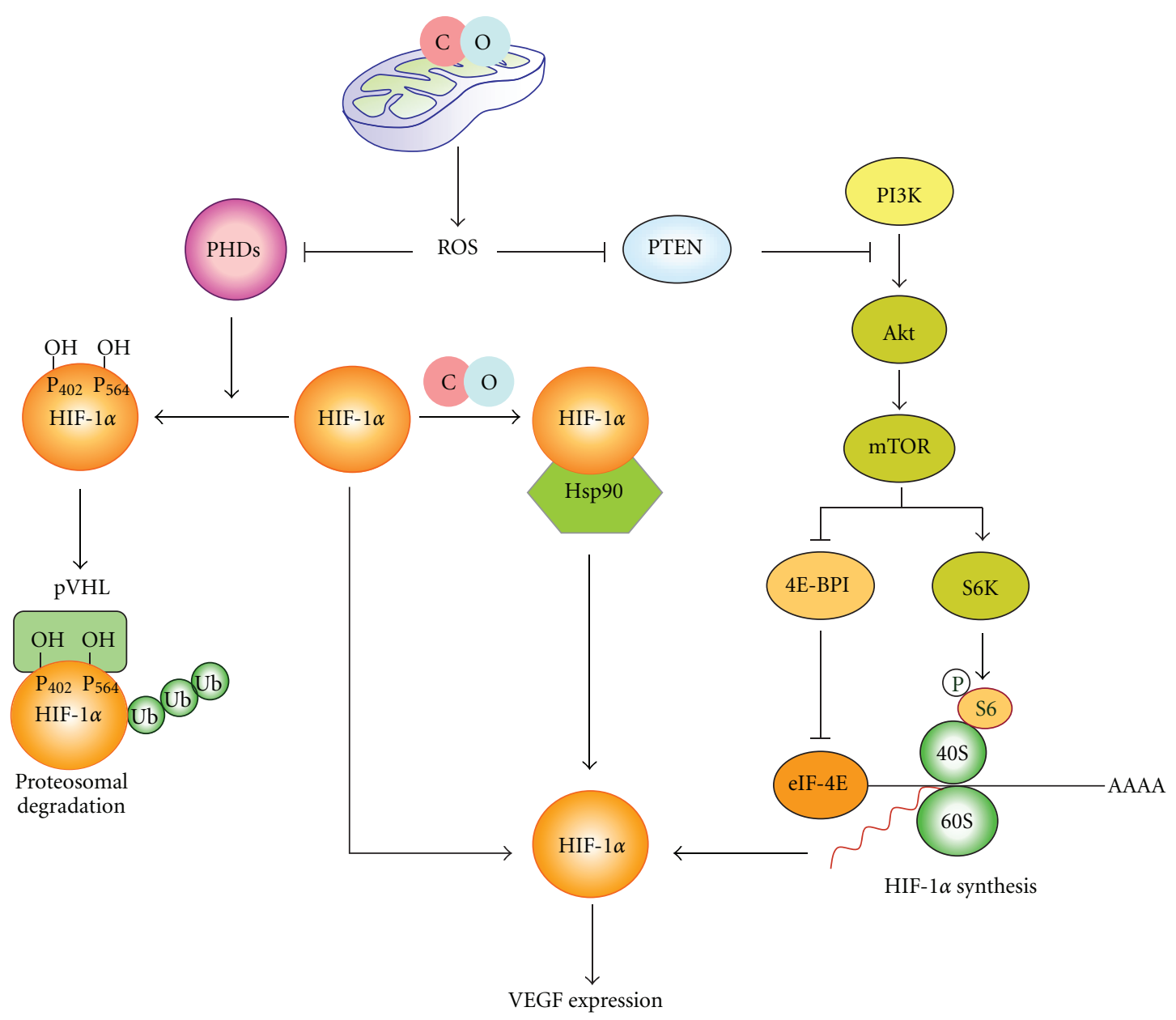

FIGURE 3: CO-induced HIF-1 $\alpha$ stabilization via ROS-dependent and -independent manners. ROS produced from mitochondria by CO inhibit PHD activity, resulting in inhibition of pVHL-mediated proteasomal degradation of HIF- $1 \alpha$. CO-mediated ROS production can inhibit PTEN, consequently activating Akt/mTOR-mediated HIF- $1 \alpha$ translation. In addition, CO directly promotes the binding of HIF$1 \alpha /$ Hsp90, which stabilizes the HIF- $1 \alpha$ protein in a ROS-independent manner.

expression, accumulates intracellular ROS and reduces PHD activity [71]. A significant amount of supportive data has proposed a role of mitochondrial ROS in the regulation of HIF- $1 \alpha$ stability [72], and the exogenous addition or endogenous expression of antioxidants is sufficient in some systems to reverse hypoxia-induced HIF- $1 \alpha$ activation. Furthermore, Bell et al. [73] have provided strength to the possibility of a role for ROS in mitochondrial signaling to the HIF pathway in hypoxia, using the mitochondrial-targeted antioxidant Mito-Q. This group demonstrated that the Qo site of the mitochondrial complex III is necessary for the generation of mitochondrial ROS in hypoxia. Critical evidence suggesting a mitochondrial oxygen sensor was revealed with the discovery that $\rho^{0}$ Hep3B cells, which contain no mitochondrial DNA and thus no electron transport, are incapable of HIF-1 DNA binding activity and erythropoietin expression following hypoxia [74]. In addition, ROS derived from Nox can be also involved in the induction of HIF- $1 \alpha$ under normoxia and hypoxia in vascular cells. Görlach et al. [75] reported that overexpression of Rac1 increased HIF- $1 \alpha$ expression through ROS. Thus, the Rac1/Nox/ROS pathway plays an important role in the upregulation of HIF- $1 \alpha$ and VEGF expression in response to VEGF and hypoxia.

$\mathrm{CO}$ has been demonstrated to increase HIF- $1 \alpha$ stability in macrophages, leading to the protection of lungs from ischemia-reperfusion injury [21]. This effect is dependent on ROS production from mitochondria and leads to increased synthesis of TGF- $\beta$ [21]. However, precise mechanisms by which CO promotes HIF- $1 \alpha$ stability and VEGF expression in ECs remain unclear. Our previous results showed that conditioned media from astrocytes treated with CORM-2 significantly increased HUVEC proliferation, migration, and tube formation, which was inhibited by treatment with a VEGF-neutralizing antibody [57]. In addition, CO increases HIF- $1 \alpha$-dependent VEGF expression in astrocytes by dual mechanisms. Firstly, CO promotes de novo protein synthesis of HIF- $1 \alpha$ through activation of the PI3-K/Akt/mTOR and MEK/ERK pathways responsible for activation of translational machinery. Secondly, CO stabilizes the HIF- $1 \alpha$ protein through functional activation of Hsp90, which inhibits proteosomal degradation by interacting with HIF-1 $\alpha$ [57]. Consistent with our data, recent studies demonstrated that 
Hsp90 $\alpha$ directly interacts with HIF- $1 \alpha$ and protects it from oxygen- and PHD-independent ubiquitination and degradation $[76,77]$ (Figure 3), resulting in elevation of HIF-1 $\alpha$ protein levels and VEGF expression. However, mechanisms by which $\mathrm{CO}$ regulates the interaction between HIF- $1 \alpha$ and Hsp90 $\alpha$ should be further investigated.

Although low concentrations of CO can rapidly stabilize HIF- $1 \alpha$ by mitochondria-dependent ROS generation [21] or by the functional activation of Hsp90 [57], high levels of CO suppressed hypoxia-induced increases in HIF-1 stability and Epo mRNA expression. CO had no effect on the elevation of HIF-1 activity and Epo expression by the free iron chelator desferrioxamine [78], indicating that $\mathrm{CO}$ acts presumably as a heme ligand binding to the oxygen sensor. In fact, $\mathrm{CO}$ decreases the binding activity of HIF-1 to hypoxiaresponsive cis-acting element of target genes without altering HIF-1 protein levels through the elevation of cGMP cellular levels [79]. The contribution of $\mathrm{CO}$ to the regulation of HIF- $1 \alpha$-dependent pathway is somewhat complicated since $\mathrm{CO}$ is reported to stabilize HIF- $1 \alpha$ in normoxia, whereas this gaseous molecule can promote HIF- $1 \alpha$ degradation under hypoxia $[80,81]$. These pieces of evidence indicate that the effect of $\mathrm{CO}$ on HIF-1 activity is dependent on multiple factors, as described above. Therefore, a delicate balance between $\mathrm{CO}$, ROS, and $\mathrm{O}_{2}$ appears to determine the collective outcome of HIF-dependent physiological events.

3.2. HO-1/CO-Induced Angiogenesis via SDF-1. HO-1/CO is closely linked to the proangiogenic effects of SDF-1. Mice exposed to CO gas (250 ppm) for 2 hours per day enhance reendothelialization after vascular injury by increasing circulating endothelial progenitor cells (EPCs) and elevating the serum level of SDF-1 [63]. SDF-1 also promotes angiogenesis via a HO-1-dependent mechanism in EPCs and aortic ECs isolated from wild-type, but not from HO- $1^{-/-}$mice [82]. HO- $1^{-/-}$ECs and EPCs show defective angiogenic responses in SDF-1-induced proliferation and migration [82], indicating that SDF-1 promotes angiogenesis via HO-1 induction. Local gene transfer of SDF-1 enhances ischemia-induced vasculogenesis and angiogenesis in vivo through elevation of VEGF expression and NO production [83], suggesting that the VEGF/eNOS pathway is critically involved in SDF-1-induced vascular remodeling. In addition, both endogenous and exogenous NO increase angiogenesis through the elevation of VEGF and SDF1 production and steady-state levels of NO [44]. These findings indicate that a positively coordinated link among HO-1/CO, eNOS, VEGF, and SDF-1 can provide new avenues for ischemia-induced neovascularization in adults. Moreover, these pieces of evidence support a vital role of HO-1 and its reaction byproduct, $\mathrm{CO}$, in vascular repair by enhancing endothelial progenitor cell mobilization.

Regulation of vascular function by SDF-1 is most likely linked to ROS generation and relative $\mathrm{O}_{2}$ availability. SDF1 did not induce chemotaxis and invasion in Nox-deficient stem and progenitor cells by blunting SDF-1-mediated phosphorylation of Akt [84]. Ceradini et al. [58] reported that recruitment of CXCR4-positive progenitor cells to regenerating tissues is mediated by hypoxic gradients via HIF- $1 \alpha$-induced expression of SDF-1, resulting in increases in adhesion, migration, and homing of circulating CXCR4positive progenitor cells to ischemic tissue. Therefore, we speculate that coordinated crosstalk among CO, ROS, and HIF- $1 \alpha$ appears to determine the collective outcome of SDF1-dependent neovascularization.

\subsection{CO-Mediated Angiogenesis and Mitochondrial Metabo-} lism. Inhibition of the respiratory chain by $\mathrm{CO}$ results in hypoxia, leading to the retardation of ATP turnover and accumulation of mitochondrial biogenic sensors. Recently, the crosslink between angiogenic factors and mitochondrial biogenic factors has become of great interest. Therefore, it would be worthwhile to describe the interrelationship between mitochondrial biogenesis and angiogenesis, which are regulated by the $\mathrm{HO}-1 / \mathrm{CO}$ pathway. Binding of $\mathrm{CO}$ to a heme moiety of COX increases mitochondrial ROS production [85], the prosurvival PI3-K/Akt pathway [86], and stimulation of mitochondrial DNA (mtDNA) replication by oxidant-dependent phosphorylation of nuclear respiratory factor 1 (NRF1) and expression of the mitochondrial transcription factor A (Tfam) [87]. Suppression of COmediated mitochondrial ROS production and Akt activation by catalase and a PI3K inhibitor has been shown to prevent binding of NRF1 to the Tfam promoter, suggesting that CO promotes mtDNA replication by elevating ROS production from mitochondria [25]. The findings indicate that $\mathrm{CO}$ and ROS play a complementary role in mitochondrial biogenesis.

An example of metabolic regulators regulated by $\mathrm{CO}$ is the PPARs, which are ligand-activated transcription factors that govern the expression of genes involved in the regulation of lipid and glucose metabolism. Three isoforms, PPAR- $\alpha$, PPAR- $\beta / \delta$, and PPAR- $\gamma$, are expressed in vascular cells and regulate vascular functions via regulation of vascular inflammation, EC function, and VSMC proliferation [88]. PPAR$\alpha$ can inhibit VSMC proliferation, while PPAR- $\beta$ activators upregulate the expression of VEGF, resulting in enhanced EC proliferation, sprouting, and tube formation $[89,90]$. PPAR$\gamma$ agonists increase VEGF expression in human VSMC cells [91] and induce EC tube formation and neovascularization in the murine corneal angiogenic model [92]. The effects of PPAR $-\gamma$ are very similar to those of CO when examined in identical experimental models, regarding anti-inflammatory and antiproliferative effects [93-95]. PPAR- $\gamma$ is upregulated by $\mathrm{CO}$ in macrophages in vitro and in vivo [24]. The suppression of CO-mediated ROS generation or accumulation by antimycin A and antioxidant (SOD and catalase) abrogated CO-induced PPAR- $\gamma$ expression, suggesting that mitochondrial ROS generation by $\mathrm{CO}$ is required for PPAR$\gamma$ induction [24]. PPAR- $\gamma$ reduces superoxide formation by upregulating $\mathrm{Cu} / \mathrm{Zn}-\mathrm{SOD}$ (SOD1) and downregulating the p22 $2^{\text {phox }}$ component of the Nox system [96] and enhances NO production by increasing eNOS phosphorylation and its interaction with Hsp90 [97]. Akin to NO, the beneficial effects of PPAR- $\alpha$ and PPAR- $\gamma$ on the vascular wall may also stem from HO-1 induction [98]. 
Another metabolic regulator is adenosine monophosphate protein kinase (AMPK), which is activated upon energy deprivation, stimulates glucose uptake, and attenuates energy-consuming processes. AMPK leads to increases in NO production via phosphorylation-dependent activation of eNOS and upregulation of VEGF levels, resulting in improved revascularization of ischemic limbs [99]. Recent studies show that a HO-1 activator, hemin, improves insulin sensitivity and glucose metabolism by enhancing adiponectin levels, AMPK activation, and translocation of glucose transporter-4 in diabetes models [100, 101]. AMPK can also enhance SIRT1 $\left(\mathrm{NAD}^{+}\right.$-dependent class III histone deacetylase) activity by increasing cellular $\mathrm{NAD}^{+}$ levels, resulting in the deacetylation and modulation of downstream SIRT1 targets, including PGC- $1 \alpha$ [102]. Modest increases in cellular CO concentrations $(150 \mathrm{pmol} / \mathrm{mg})$ activate mitochondrial biogenesis via upregulation of PGC- $1 \alpha$ by increasing mitochondrial ROS production and activating sGC and Akt in mouse hearts [25].

Therefore, the HO-1/CO pathway controls vascular homeostasis and mitochondrial biogenesis by regulating ROS generation and metabolic modulators (PPARs, AMPK, SIRT1, and PGC-1 $\alpha$ ). These lines of evidence suggest that CO acts as an extraordinary signaling molecule by regulating not only angiogenesis but also mitochondrial energy metabolism in a ROS-dependent manner.

\section{Role of CO in Vasculopathy and Stroke}

HO-1 is one of the most redox-sensitive genes described in nature so far; its expression is regulated by an array of conditions that are associated with a moderate or persistent imbalance of the intracellular redox state, which is the common denominator in the development of most human pathologies. Elevation of intracellular ROS levels activates the Nrf2 pathway and induces $\mathrm{HO}-1$, leading to $\mathrm{CO}$ production [103]. In addition, $\mathrm{CO}$ produced by $\mathrm{HO}-1$ or exogenous delivery also increases the transcriptional induction of HO-1, probably by mitochondrial ROS generation [104]. These results indicate that there is positive circuit between $\mathrm{ROS} / \mathrm{Nrf2}$ and $\mathrm{HO}-1 / \mathrm{CO}$ pathways, leading to continuous production of $\mathrm{CO}$. Endogenous and exogenous $\mathrm{CO}$ protects cells from cytotoxicity induced by pathological levels of ROS, which is an important factor in the pathogenesis of human diseases, including atherosclerosis, restenosis, neointimal hyperplasia, and stroke.

4.1. CO in Vascular Disorders. Atherosclerosis, restenosis, and neointimal hyperplasia are the most common vascular disorders and result in significant long-term morbidity and mortality. Their pathogenesis is multifactorial and the common initiating event appears to be endothelial dysfunction and subsequent overproliferation of the underlying SMCs. $\mathrm{CO}$ has emerged as a potently protective, homeostatic molecule that prevents the development of vascular disorders when administered prophylactically. Growing evidence reveals a close relationship between oxidative stress and endothelial dysfunction [105]. Enhanced ROS production and decreased antioxidant levels potentially contribute to endothelial dysfunction by regulating NO production, vascular inflammation, and apoptosis. In addition, ROS promotes vascular remodeling via stimulation of VSMC proliferation. However, CO improves function, proliferation, and survival of ECs, but inhibits VSMC proliferation [106]. These observations suggest that the $\mathrm{HO}-1 / \mathrm{CO}$ pathway prevents vascular disorders via improvement of endothelial function and suppression of VSMC proliferation.

Aortic transplantation in $\mathrm{HO}-1$-deficient mice results in $100 \%$ mortality within 4 days as a consequence of severe arterial thrombosis. Notably, treatment of these mice with CORM-2 considerably improved survival (62\% survival at $>56$ days) [107]. HO-1 gene transfer into the vessel wall or systemic CO delivery resulted in a significant reduction in intimal hyperplasia in a rat model of allogenic aorta transplantation compared to controls by decreasing leukocyte activation, adhesion molecule expression, and VSMC accumulation in the intima [108]. HO-1 gene transfer and CO delivery showed a reduction in the number of leukocytes and expression of adhesion molecules and cytokines, with gene transfer treatment displaying a more pronounced effect than $\mathrm{CO}$ treatment. Conversely, $\mathrm{CO}$ exerts a greater inhibitory effect on VSMC accumulation in the intima than HO-1 gene delivery. These studies indicate that the beneficial effects of HO-1 gene expression on vascular inflammation and VSMC proliferation are associated with CO production, but possibly also with other antioxidant end products (biliverdin and bilirubin) from heme degradation by HO-1.

Higher levels of HO-1 expression exhibit a lower restenosis and cardiac vasculopathy after balloon angioplasty and heart transplantation compared with low HO-1 response to stress stimuli $[109,110]$. In addition, direct exposure to CO suppresses restenosis after carotid balloon injury in rats and mice, which is closely associated with a strong inhibition of VSMC proliferation, constrictive neointimal hyperplasia, and recurrent lumen narrowing [111]. These effects probably elicit the generation of cGMP, activation of p38 MAPK, and upregulation of the cyclin-dependent protein kinase inhibitor p21 [111]. It has been also shown that probucol, a drug used to prevent restenosis, inhibits intimal thickening by inhibiting the proliferation of VSMCs via induction of HO-1 [112]. These evidences indicate that the HO-1/CO pathway plays an important role in the suppressive effect on VSMC proliferation, subsequently preventing neointimal hyperplasia and restenosis.

Inhalation of authentic $\mathrm{CO}$ gas suppresses established pulmonary arterial hypertension by upregulating eNOS expression and NO production, as well as elicits a simultaneous increase in apoptosis and decrease in VSMC proliferation [113], supporting the use of CO clinically to treat pulmonary hypertension and vasculopathy. $\mathrm{CO}$ gas activates the Akt-eNOS-retinoblastoma axis, which is responsible for survival, proliferation, and migration of ECs, leading to the promotion of reendothelialization [106]. CO accelerates reendothelialization following balloon angioplasty in rats and wire injury in mice, and neovascularization does not occur in mice lacking eNOS, suggesting that $\mathrm{CO}$ requires $\mathrm{NO}$ to enhance reendothelialization of denuded vessels 
[106]. CORM-3 causes a rapid and prompt vasorelaxation and hypotension via a cGMP-dependent and endotheliumdependent manner [51]. In concert with NO, CO-releasing compounds exert therapeutically beneficial effects on vascular damage and dysfunction, which cause hypotension, intimal hyperplasia, and restenosis, by promoting vasorelaxation and reendothelialization.

It has been shown that HO-1 downregulates expression of vascular inflammatory molecules, such as ICAM-1, VCAM-1, and E-selectin in TNF- $\alpha$-stimulated ECs [114], consequently blocking attachment of monocytes/leukocytes to endothelium and inhibiting subsequent transmigration across the subendothelial basal lamina. CORM-2-liberated CO significantly reduced LPS-induced ROS generation, NF$\kappa \mathrm{B}$ activation, and ICAM-1 expression in primary cultured HUVECs (Figure 4(a)), resulting in a decrease in interaction between neutrophils and LPS-stimulated HUVECs (Figure 4(b)) [115]. We have recently found that the $\mathrm{HO}-1 / \mathrm{CO}$ pathway suppresses expression of the adhesion molecules, ICAM- 1 and VCAM-1, in TNF- $1 \alpha$-stimulated human ECs by inhibiting intracellular ROS levels and NF$\kappa \mathrm{B}$ activation [116] (Figure 4). Moreover, in vivo induction of HO-1 by specific Keap-1 knockdown reduced the expression of ICAM-1 and VCAM-1 in endotoxemic mice, leading to the protection from liver and lung injuries and lethality [117]. NF- $\kappa$ B plays a crucial function in the expression of various inflammatory genes, such as cytokine genes and adhesion molecules. This transcription factor is activated by two distinct signaling pathways, receptormediated phosphorylation-dependent signal cascade [118] and ROS-mediated redox cascade [119]. CO downregulates phosphorylation-dependent NF- $\kappa \mathrm{B}$ (canonical pathway) activation by increasing interaction between caveolin1 and TLR4 in LPS-stimulated macrophages (Figure 4), preventing TLR4 association with MyD88. The association between TLR4 and MyD88 activates $\mathrm{I} \kappa \mathrm{B}$ kinase activity, leading to NF- $\kappa \mathrm{B}$ activation via p65 phosphorylation and nuclear translocation $[120,121]$. On the other hand, CO inhibits NADPH oxidase activity and ROS generation in LPS-simulated macrophages [51]. Similarly, we also found that $\mathrm{HO}-1 / \mathrm{CO}$ inhibited cellular levels of ROS, which play a role of intracellular signal molecules in activating NF- $\kappa \mathrm{B}$ activation for adhesion molecule expression, in TNF- $\alpha$-stimulated HUVECs $[117,122]$. These observations indicate that HO-1 induction or $\mathrm{CO}$ delivery can regulate inflammation-mediated vascular disorders, including atherosclerosis, via suppression of $\mathrm{NF}-\kappa \mathrm{B}$ activation by inhibiting both NADPH oxidase-mediated ROS generation and phosphorylation-dependent cascade.

Although $\mathrm{HO}-1 / \mathrm{CO}$ can accelerate pathologic conditions (tumor and retinopathy) via persistent angiogenic vascular activation, HO-1 induction or exogenous CO delivery imparts potent cytoprotective and homeostatic actions in preclinical models. The beneficial activities mediated by HO$1 / \mathrm{CO}$ play a key role in regulating EC function, VSMC proliferation, and inflammation responsible for pathogenesis of vascular diseases, such as hypertension, restenosis, and atherosclerosis in part by regulating ROS-mediated multiple signal pathways.
4.2. $\mathrm{CO}$ in Stroke. The involvement of the $\mathrm{HO} / \mathrm{CO}$ system has received a considerable amount of attention as a target for therapeutic interventions against degenerative and inflammatory diseases in the central nervous system, including stroke. Stroke is a clinical condition in which the blood supply to the brain is limited or severed by embolism and blood clotting or by the rupture of blood vessels and subsequent cerebral hemorrhage. Brain ECs closely interact with other types of cells, such as astrocytes, microglia, and neurons, to form a functional "neurovascular unit," which maintains proper brain homeostasis. Free heme released from hemoglobin of erythrocytes following cerebral hemorrhage may contribute to oxidative toxicity [123]. Heme toxicity has been shown to occur in ECs [124] and brain cells [125].

Although protective in pathological conditions, $\mathrm{HO}$ is not suggested to be as beneficial for neurons as it is for other cell types. Free heme levels are thought to increase with ischemic insults due to the hydrolysis of heme proteins. Astrocytes isolated from HO-1-deficient animals were more vulnerable to the toxicity of hemoglobin and to hemin than wild-type cells [126, 127]. HO-1 is essential for the resistance of astrocytes to hemoglobin but has no protective effect in neurons. As a consequence of the differential effects of HO-1 in neurons and in astrocytes, it can be important to induce HO-1 overexpression selectively in astrocytes. An interesting approach has been utilized to express HO- 1 in astrocytes using the glial fibrillary acidic protein (GFAP) promoter. Ad-GFAP-HO-1 gene transfer resulted in exclusive overexpression of HO-1 in astrocytes, but not in neurons and was able to reduce hemin-induced cell death [128]. In contrast to HO-1, HO-2 gene deletion attenuated oxidative stress of neurons exposed to heme, thus suggesting that HO-2/CO exacerbates oxidative injury of neuronal cells by cerebral hemorrhage [129-131].

However, many recent studies using stroke models suggest cytoprotective effects of $\mathrm{HO}-1$ and $\mathrm{HO}-2$, both in neurons and astrocytes. These conflicting results may arise since $\mathrm{HO}$ products can reduce or induce oxidative damage, depending on the concentration and environment. HO- 1 induction is generally considered an adaptive cytoprotective response against the toxicity of oxidative stress. Overexpression of HO-1 in the mouse brain reveals a reduction in infarct volumes induced by middle cerebral artery occlusion [132]. When challenged acutely with the excitotoxic amino acid glutamate, the viability of primary neuronal cells from $\mathrm{HO}-1-k n o c k o u t$ mice was lowered, compared with those of wild type [133]. HO-1 overexpression also significantly protected neurons from glutamate- and $\mathrm{H}_{2} \mathrm{O}_{2}$-induced cell death [134]. Inducible HO-1 is not normally detectable in an unaffected brain, whereas constitutive HO-2 is highly expressed in brain cells, neurons, astrocytes, and cerebral ECs $[135,136]$ and appears to play an important role in the protection of the brain from stroke. HO-2 appears to protect against lipid peroxidation-mediated cell loss and impaired motor recovery after traumatic brain injury [137], whereas its deletion exacerbated cerebral hemorrhage-induced brain edema [138]. These lines of evidence indicate that 


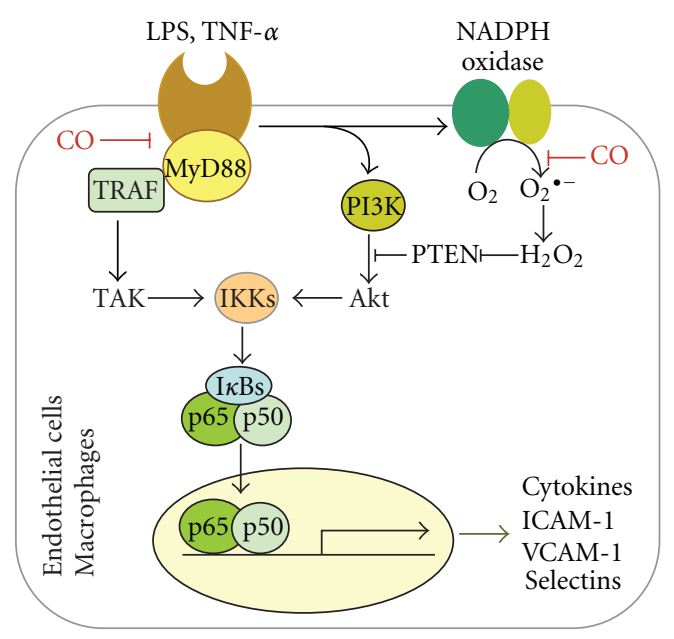

(a)

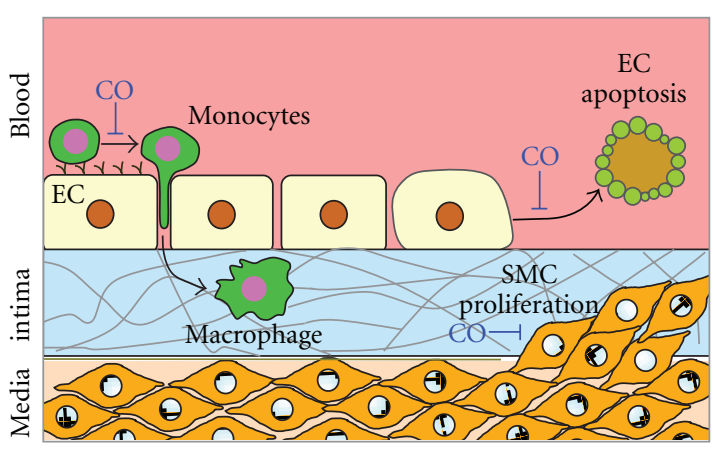

(b)

FIgURE 4: CO prevents inflammatory responses via inhibition of NF- $\kappa$ B signaling pathway. (a) Inflammatory stimuli such as TNF- $\alpha$ and LPS lead to activation of ECs, which in turn activate inflammatory signaling cascades. The association between TLR4 and MyD88 inhibits $\mathrm{I} \kappa \mathrm{B}$ kinase activity, leading to NF- $\kappa \mathrm{B}$ activation via p65/p50 nuclear translocation in TNF- $\alpha$-stimulated ECs. CO significantly reduces TNF$\alpha$-induced Nox-mediated ROS generation, NF- $\kappa$ B activation and the expression of adhesion molecules such as ICAM-1, VCAM-1, and selectins. (b) Inflammatory stimuli induce (i) the recruitment of monocytes to the endothelium, thereby promoting their transmigration into the arterial intima, (ii) ECs apoptosis and (iii) VSMC proliferation. CO diminishes this inflammatory activation by reducing the expression of adhesion molecules, stimulating EC survival and inhibiting VSMC proliferation.

both HO-1 and HO-2 protect neuronal cells and cerebral ECs from glutamate- and ROS-mediated cell death.

Ischemic stroke resulting from vascular disorders induces several biochemical and cellular reactions such as increased ROS production, inflammatory response, impairment of blood-brain barrier, and calcium overload. During reperfusion, ROS concentration is further raised to a peak point, which causes cytotoxicity through lipid peroxidation, oxidation of proteins, and DNA fragmentation [139, 140]. Increasing evidence has considered HO-1, Hsp70, antiapoptotic Bcl-2 family, and antioxidant enzymes as a therapeutic funnel in a number of pathophysiological situations and has labeled these several protective genes as the "vitagene system" [141]. Exogenous treatment of CO increases Hsp70 expression by elevating p38 MPAK activity and subsequent nuclear translocation of HSF-1 and protects ECs from TNF- $\alpha$-induced apoptosis [142] and retinal cells form ischemia/reperfusion injury [143]. In addition, exogenous $\mathrm{CO}$ increases the expression of antiapoptotic Bcl-2 and Bcl- $\mathrm{X}_{\mathrm{L}}$ in an animal model and cultured $\mathrm{ECs}$ and protects mice from ischemia/reperfusion injury [144]. HO-1 overexpression has been also shown to be neuroprotective in a model of permanent middle cerebral artery by increasing Bcl-2 levels in neurons [132]. A recent study demonstrates that $\mathrm{CO}$ protects astrocytes against oxidative stress-induced apoptosis by improving metabolic functions, namely: (i) inhibition of apoptosis, (ii) stimulation of COX activity, and (iii) mitochondrial biogenesis, particularly enhancing Bcl-2 expression [145]. Treatment of mice with the water-soluble CO-releasing molecule CORM3 significantly increases expression of extracellular SOD and
cFLIP $_{\mathrm{L} / \mathrm{s}}$, compared with control mice. Moreover, CORM-3 induced a delayed protection against myocardial infarction similar to that observed in the late phase of ischemic preconditioning [146]. Therefore, $\mathrm{HO}-1 / \mathrm{CO}$ can protect against ischemic stroke and other oxidative neuronal cytotoxicity by upregulating the expression of vitagenes.

\section{Therapeutic Effects of CO}

There is an abundance of preclinical evidence in large and small animals demonstrating the beneficial effects of $\mathrm{CO}$, administered as an authentic $\mathrm{CO}$ gas or as a COreleasing molecule CORM, in cardiovascular disease, stroke, sepsis, transplanted organ rejection, and acute organ injury $[35,147]$. The first single, blinded, randomized, placebocontrolled Phase I trial to evaluate the clinical safety and pharmacokinetics of inhaled $\mathrm{CO}$ in healthy humans has recently been completed (reviewed in [35]). Authentic CO gas has been evaluated for safety in Phase I, testing in healthy humans with rigorous dose-escalation studies and was acceptable for Phase II testing, which is currently ongoing. Since a larger number of people are studied, further information is gained on safety during this study. In addition, the Phase III study is currently evaluating the safety and potential efficacy of inhaled CO in subjects with severe pulmonary arterial hypertension.

The technology is now in place to bring $\mathrm{CO}$ to clinical applications in the form of inhaled gaseous therapy or through the use of potentially parenteral and orally active CORMs. CO gas is nonreactive, inexpensive, and straightforward to produce and thus is easily administrated as an 
inhaled gas similar to NO, which is already used clinically [35]. CO gas is not metabolized and reversibly binds to cellular targets. Tissue levels of CO were transient and followed similar elimination kinetics. Under normoxic conditions, CO has a half-life of 3-7 hours in human volunteers, and elimination of $\mathrm{CO}$ is strictly through exhalation in the lungs with no further metabolism [35]. However, clinicians must consider that the critical concentration of upper limit of carboxyhaemoglobin is $14.3 \%$ in human blood, which can be reached following inhalation of $3 \mathrm{mg}$ of $\mathrm{CO}$ per $\mathrm{kg}$ for a 1 hour.

By contrast, all CORMs possess a backbone carrier moiety that will need to be stringently characterized from a metabolic and toxicological standpoint. Several CORMs have been synthesized for therapeutic agents aimed at delivering controlled amounts of $\mathrm{CO}$ to tissues and organs [148]. CORM-1 is soluble and stable in water giving an approximate $\mathrm{pH}$ of 11 and decomposes rapidly releasing $\mathrm{CO}$ under physiological condition with slow kinetics $\left(t_{1 / 2}=\right.$ $21 \mathrm{~min}$ ) [149]. CORM-2 is soluble in DMSO and olive oil and releases CO by photodissociation [148]. On the other hand, CORM-3 is a water-soluble CO-releasing agent with half-life of $1 \mathrm{~min}$ [150]. These compounds release CO and promote vasorelaxation and hypotension via activation of cGC and potassium channel, resulting in the improvement of vascular function. In addition, $\mathrm{CO}$ released from CORMs inhibits NF- $\kappa \mathrm{B}$-mediated expression of inflammatory genes and upregulates expression of adaptive genes for oxidative stress. Therefore, CO-releasing compounds can be used for therapeutic treatment of vascular diseases, inflammationassociated diseases, and oxidative stress-induced disorders.

\section{Summary}

The significant actions of biological gaseous molecules, such as $\mathrm{CO}$ and $\mathrm{NO}$, generated by $\mathrm{HO}$ and NOS, respectively, have attracted substantial interest. The reciprocal interactions between CO and NO are complex, dynamic, and adaptable. Numerous experiments demonstrate that $\mathrm{CO}$ is involved in cellular adaptation to oxidative stress and vascular dysfunction, leading to the maintenance of cellular and vascular homeostasis. $\mathrm{CO}$ produced by $\mathrm{HO}$ can stimulate a prooxidant milieu in aerobic cells by promoting ROS-dependent signaling, resulting in the activation of redox-sensitive transcription factors such as HIF-1 $\alpha$. CO signaling through the regulation of ROS production has been implicated in a number of cellular regulatory processes, including cell proliferation, angiogenesis, mitochondrial biogenesis, and adaptation to oxidative stress. In addition, $\mathrm{CO}$ elicits a beneficial effect in animal models of oxidative injury, vascular diseases, and stroke. Although CORMs have been developed for tissue-selective agents for disease-specific treatments, CORMs and CO gas are still in the early stages of clinical treatment. As a consequence, understanding the mechanism by which $\mathrm{CO}$ regulates oxidative stress and vascular function will assist in the medical battle against vascular diseases and oxidative stress.

\section{Abbreviations}

$\begin{array}{ll}\text { CO: } & \text { Carbon monoxide } \\ \text { HO: } & \text { Heme oxygenase } \\ \text { ROS: } & \text { Reactive oxygen species } \\ \text { NOS: } & \text { Nitric oxide synthase } \\ \text { COX: } & \text { Cytochrome c oxidase } \\ \text { SOD: } & \text { Superoxide dismutase } \\ \text { HIF: } & \text { Hypoxia-inducible factor } \\ \text { VEGF: } & \text { Vascular endothelial growth factor } \\ \text { IL-18: } & \text { Interleukin-18 } \\ \text { SDF-1: } & \text { Stromal-derived factor-1 } \\ \text { sEng: } & \text { Soluble endoglin } \\ \text { PPAR- } \gamma: & \text { Peroxisome-proliferator-activated receptor- } \gamma \\ \text { PGC-1 } \alpha: \text { PPAR- } \gamma \text { coactivator-1 } \alpha \\ \text { HKa: } & \text { High-molecular-weight kininogen } \\ \text { Nox: } & \text { NADPH oxidase } \\ \text { EC: } & \text { Endothelial cell } \\ \text { HUVEC: Human umbilical vein endothelial cell } \\ \text { VSMC: } & \text { Vascular smooth muscle cell } \\ \text { EPC: } & \text { Endothelial progenitor cell } \\ \text { sGC: } & \text { Soluble guanylyl cyclase } \\ \text { NF- } \kappa \text { B: } & \text { Nuclear factor- } \kappa \text { B } \\ \text { TLR4: } & \text { Toll-like receptor } 4 \\ \text { TNF- } \alpha: & \text { Tumor necrosis factor- } \alpha .\end{array}$

\section{Acknowledgment}

This work was supported by the Korea Science and Engineering Foundation Grant funded by the Korea government (MOST) (M10642140004-06N4214-0040).

\section{References}

[1] N. Hill-Kapturczak, S. H. Chang, and A. Agarwal, "Heme oxygenase and the kidney," DNA and Cell Biology, vol. 21, no. 4, pp. 307-321, 2002.

[2] M. L. Wu, Y. C. Ho, and S. F. Yet, "A central role of heme oxygenase-1 in cardiovascular protection," Antioxidants \& Redox Signaling, vol. 15, no. 7, pp. 1835-1846, 18352011.

[3] Y. M. Kim, H. Bergonia, and J. R. Lancaster, "Nitrogen oxideinduced autoprotection in isolated rat hepatocytes," FEBS Letters, vol. 374, no. 2, pp. 228-232, 1995.

[4] G. M. Trakshel and M. D. Maines, "Multiplicity of heme oxygenase isozymes. HO-1 and HO-2 are different molecular species in rat and rabbit," Journal of Biological Chemistry, vol. 264, no. 2, pp. 1323-1328, 1989.

[5] T. Yoshida and M. Sato, "Posttranslational and direct integration of heme oxygenase into microsomes," Biochemical and Biophysical Research Communications, vol. 163, no. 2, pp. 1086-1092, 1989.

[6] R. Tenhunen, H. S. Marver, and R. Schmid, "The enzymatic conversion of heme to bilirubin by microsomal heme oxygenase," Proceedings of the National Academy of Sciences of the United States of America, vol. 61, no. 2, pp. 748-755, 1968.

[7] H. W. Hwang, J. R. Lee, K. Y. Chou et al., "Oligomerization is crucial for the stability and function of heme oxygenase-1 in the endoplasmic reticulum," Journal of Biological Chemistry, vol. 284, no. 34, pp. 22672-22679, 2009. 
[8] A. Verma, D. J. Hirsch, C. E. Glatt, G. V. Ronnett, and S. H. Snyder, "Carbon monoxide: a putative neural messenger," Science, vol. 259, no. 5093, pp. 381-384, 1993.

[9] N. Ma, X. Ding, M. Doi, N. Izumi, and R. Semba, "Cellular and subcellular localization of heme oxygenase-2 in monkey retina," Journal of Neurocytology, vol. 33, no. 4, pp. 407-415, 2004.

[10] Q. Lin, S. Weis, G. Yang et al., "Heme oxygenase-1 protein localizes to the nucleus and activates transcription factors important in oxidative stress," Journal of Biological Chemistry, vol. 282, no. 28, pp. 20621-20633, 2007.

[11] S. Bindu, C. Pal, S. Dey et al., "Translocation of heme oxygenase-1 to mitochondria is a novel cytoprotective mechanism against non-steroidal antiinflammatory druginduced mitochondrial oxidative stress, apoptosis, and gastric mucosal injury," Journal of Biological Chemistry, vol. 286, no. 45, pp. 39387-39402, 2011.

[12] H. P. Kim, X. Wang, F. Galbiati, S. W. Ryter, and A. M. K. Choi, "Caveolae compartmentalization of hemeoxygenase-1 in endothelial cells," The FASEB Journal, vol. 18, no. 10, pp. 1080-1089, 2004.

[13] M. Kajimura, R. Fukuda, R. M. Bateman, T. Yamamoto, and M. Suematsu, "Interactions of multiple gas-transducing systems: hallmarks and uncertainties of $\mathrm{CO}, \mathrm{NO}$, and $\mathrm{H}_{2} \mathrm{~S}$ Gas Biology," Antioxidants and Redox Signaling, vol. 13, no. 2, pp. 157-192, 2010.

[14] H. J. Vreman, R. J. Wong, C. A. Sanesi, P. A. Dennery, and D. K. Stevenson, "Simultaneous production of carbon monoxide and thiobarbituric acid reactive substances in rat tissue preparations by an iron-ascorbate system," Canadian Journal of Physiology and Pharmacology, vol. 76, no. 12, pp. 1057-1065, 1998.

[15] R. R. Engel, J. M. Matsen, S. S. Chapman, and S. Schwartz, "Carbon monoxide production from heme compounds by bacteria," Journal of Bacteriology, vol. 112, no. 3, pp. 1310 1315, 1972.

[16] C. I. Jones, Z. Han, T. Presley et al., "Endothelial cell respiration is affected by the oxygen tension during shear exposure: role of mitochondrial peroxynitrite," American Journal of Physiology, vol. 295, no. 1, pp. C180-C191, 2008.

[17] M. Ushio-Fukai and Y. Nakamura, "Reactive oxygen species and angiogenesis: NADPH oxidase as target for cancer therapy," Cancer Letters, vol. 266, no. 1, pp. 37-52, 2008.

[18] G. Yuan, J. Nanduri, S. Khan, G. L. Semenza, and N. R. Prabhakar, "Induction of HIF- $1 \alpha$ expression by intermittent hypoxia: involvement of NADPH oxidase, $\mathrm{Ca}^{+}$signaling, prolyl hydroxylases, and mTOR," Journal of Cellular Physiology, vol. 217, no. 3, pp. 674-685, 2008.

[19] J. Dulak, J. Deshane, A. Jozkowicz, and A. Agarwal, "Heme oxygenase- 1 and carbon monoxide in vascular pathobiology: focus on angiogenesis," Circulation, vol. 117, no. 2, pp. 231241, 2008.

[20] M. Cudmore, S. Ahmad, B. Al-Ani et al., "Negative regulation of soluble Flt-1 and soluble endoglin release by heme oxygenase-1," Circulation, vol. 115, no. 13, pp. 1789-1797, 2007.

[21] B. Y. Chin, G. Jiang, B. Wegiel et al., "Hypoxia-inducible factor $1 \alpha$ stabilization by carbon monoxide results in cytoprotective preconditioning," Proceedings of the National Academy of Sciences of the United States of America, vol. 104, no. 12, pp. 5109-5114, 2007.

[22] A. Loboda, A. Jazwa, A. Grochot-Przeczek et al., "Heme oxygenase-1 and the vascular bed: from molecular mechanisms to therapeutic opportunities," Antioxidants and Redox Signaling, vol. 10, no. 10, pp. 1767-1812, 2008.
[23] L. G. Coffman, D. Parsonage, R. D’Agostino Jr., F. M. Torti, and S. V. Torti, "Regulatory effects of ferritin on angiogenesis," Proceedings of the National Academy of Sciences of the United States of America, vol. 106, no. 2, pp. 570-575, 2009.

[24] M. Bilban, F. H. Bach, S. L. Otterbein et al., "Carbon monoxide orchestrates a protective response through PPAR $\gamma$," Immunity, vol. 24, no. 5, pp. 601-610, 2006.

[25] H. B. Suliman, M. S. Carraway, L. G. Tatro, and C. A. Piantadosi, "A new activating role for CO in cardiac mitochondrial biogenesis," Journal of Cell Science, vol. 120, no. 2, pp. 299308, 2007.

[26] S. Lancel, S. M. Hassoun, R. Favory, B. Decoster, R. Motterlini, and R. Neviere, "Carbon monoxide rescues mice from lethal sepsis by supporting mitochondrial energetic metabolism and activating mitochondrial biogenesis," Journal of Pharmacology and Experimental Therapeutics, vol. 329, no. 2, pp. 641-648, 2009.

[27] B. Brune and V. Ullrich, "Inhibition of platelet aggregation by carbon monoxide is mediated by activation of guanylate cyclase," Molecular Pharmacology, vol. 32, no. 4, pp. 497-504, 1987.

[28] S. Basuroy, D. Tcheranova, S. Bhattacharya, C. W. Leffler, and H. Parfenova, "Nox4 NADPH oxidase-derived reactive oxygen species, via endogenous carbon monoxide, promote survival of brain endothelial cells during TNF- $\alpha$-induced apoptosis," American Journal of Physiology, vol. 300, no. 2, pp. C256-C265, 2011.

[29] L. C. Petersen, "The effect of inhibitors on the oxygen kinetics of cytochrome c oxidase," Biochimica et Biophysica Acta, vol. 460, no. 2, pp. 299-307, 1977.

[30] D. Pankow and W. Ponsold, "Effect of carbon monoxide exposure on heart cytochrome c oxidase activity of rats," Biomedica Biochimica Acta, vol. 43, no. 10, pp. 1185-1189, 1984.

[31] M. Bilban, A. Haschemi, B. Wegiel, B. Y. Chin, O. Wagner, and L. E. Otterbein, "Heme oxygenase and carbon monoxide initiate homeostatic signaling," Journal of Molecular Medicine, vol. 86, no. 3, pp. 267-279, 2008.

[32] M. Bilban, A. Haschemi, B. Wegiel, B. Y. Chin, O. Wagner, and L. E. Otterbein, "Heme oxygenase and carbon monoxide initiate homeostatic signaling," Journal of Molecular Medicine, vol. 86, no. 3, pp. 267-279, 2008.

[33] E. A. Veal, A. M. Day, and B. A. Morgan, "Hydrogen peroxide sensing and signaling," Molecular Cell, vol. 26, no. 1, pp. 1-14, 2007.

[34] C. Taillé, J. El-Benna, S. Lanone, J. Boczkowski, and R. Motterlini, "Mitochondrial respiratory chain and NAD $(\mathrm{P}) \mathrm{H}$ oxidase are targets for the antiproliferative effect of carbon monoxide in human airway smooth muscle," Journal of Biological Chemistry, vol. 280, no. 27, pp. 25350-25360, 2005.

[35] R. Motterlini and L. E. Otterbein, "The therapeutic potential of carbon monoxide," Nature Reviews Drug Discovery, vol. 9, no. 9, pp. 728-743, 2010.

[36] A. Yachie, Y. Niida, T. Wada et al., "Oxidative stress causes enhanced endothelial cell injury in human heme oxygenase1 deficiency," Journal of Clinical Investigation, vol. 103, no. 1, pp. 129-135, 1999.

[37] M. Ushio-Fukai, "VEGF signaling through NADPH oxidasederived ROS," Antioxidants and Redox Signaling, vol. 9, no. 6, pp. 731-739, 2007.

[38] I. Takac, K. Schroder, and R. P. Brandes, "The Nox family of NADPH oxidases: friend or foe of the vascular system?" Current Hypertension Reports, vol. 14, no. 1, pp. 70-78, 2012. 
[39] K. Nakahira, P. K. Hong, H. G. Xue et al., "Carbon monoxide differentially inhibits TLR signaling pathways by regulating ROS-induced trafficking of TLRs to lipid rafts," Journal of Experimental Medicine, vol. 203, no. 10, pp. 2377-2389, 2006.

[40] M. M. Desouki, M. Kulawiec, S. Bansal, G. M. Das, and K. K. Singh, "Cross talk between mitochondria and superoxide generating NADPH oxidase in breast and ovarian tumors," Cancer Biology and Therapy, vol. 4, no. 12, pp. 1367-1373, 2005.

[41] R. Rathore, Y. M. Zheng, C. F. Niu et al., "Hypoxia activates NADPH oxidase to increase [ROS]i and $\left[\mathrm{Ca} 2^{+}\right] \mathrm{i}$ through the mitochondrial ROS-PKCeopen signaling axis in pulmonary artery smooth muscle cells," Free Radical Biology and Medicine, vol. 45, no. 9, pp. 1223-1231, 2008.

[42] B. D. Lamon, F. F. Zhang, N. Puri, S. V. Brodsky, M. S. Goligorsky, and A. Nasjletti, "Dual pathways of carbon monoxide-mediated vasoregulation: modulation by redox mechanisms," Circulation Research, vol. 105, no. 8, pp. 775$783,2009$.

[43] B. Brüne and J. Zhou, "Hypoxia-inducible factor- $1 \alpha$ under the control of nitric oxide," Methods in Enzymology, vol. 435, pp. $463-478,2007$.

[44] S. R. Thom, Y. A. Xu, and H. Ischiropoulos, "Vascular endothelial cells generate peroxynitrite in response to carbon monoxide exposure," Chemical Research in Toxicology, vol. 10, no. 9, pp. 1023-1031, 1997.

[45] C. Thorup, C. L. Jones, S. S. Gross, L. C. Moore, and M. S. Goligorsky, "Carbon monoxide induces vasodilation and nitric oxide release but suppresses endothelial NOS," American Journal of Physiology, vol. 277, no. 6, pp. F882F889, 1999.

[46] Y. M. Kim, H. A. Bergonia, C. Muller, B. R. Pitt, W. D. Watkins, and J. R. Lancaster, "Loss and degradation of enzyme-bound heme induced by cellular nitric oxide synthesis," Journal of Biological Chemistry, vol. 270, no. 11, pp. 5710-5713, 1995.

[47] Q. A. Albakri and D. J. Stuehr, "Intracellular assembly of inducible NO synthase is limited by nitric oxide-mediated changes in heme insertion and availability," Journal of Biological Chemistry, vol. 271, no. 10, pp. 5414-5421, 1996.

[48] K. A. White and M. A. Marletta, "Nitric oxide synthase is a cytochrome P-450 type hemoprotein," Biochemistry, vol. 31, no. 29, pp. 6627-6631, 1992.

[49] M. Suematsu, N. Goda, T. Sano et al., "Carbon monoxide: an endogenous modulator of sinusoidal tone in the perfused rat liver," Journal of Clinical Investigation, vol. 96, no. 5, pp. 2431-2437, 1995.

[50] T. Imai, T. Morita, T. Shindo et al., "Vascular smooth muscle cell-directed overexpression of heme oxygenase-1 elevates blood pressure through attenuation of nitric oxide-induced vasodilation in mice," Circulation Research, vol. 89, no. 1, pp. 55-62, 2001.

[51] R. Foresti, J. Hammad, J. E. Clark et al., "Vasoactive properties of CORM-3, a novel water-soluble carbon monoxidereleasing molecule," British Journal of Pharmacology, vol. 142, no. 3, pp. 453-460, 2004.

[52] T. Morita, M. A. Perrella, M. E. Lee, and S. Kourembanas, "Smooth muscle cell-derived carbon monoxide is a regulator of vascular cGMP," Proceedings of the National Academy of Sciences of the United States of America, vol. 92, no. 5, pp. 1475-1479, 1995.

[53] S. W. Ryter, D. Morse, and A. M. Choi, "Carbon monoxide: to boldly go where NO has gone before," Science's STKE, vol. 2004, no. 230, p. RE6, 2004.
[54] R. Foresti and R. Motterlini, "The heme oxygenase pathway and its interaction with nitric oxide in the control of cellular homeostasis," Free Radical Research, vol. 31, no. 6, pp. 459475, 1999.

[55] B. S. Zuckerbraun, T. R. Billiar, S. L. Otterbein et al., "Carbon monoxide protects against liver failure through Nitric oxide-induced heme Oxygenase 1," Journal of Experimental Medicine, vol. 198, no. 11, pp. 1707-1716, 2003.

[56] G. L. Semenza, “Targeting HIF-1 for cancer therapy," Nature Reviews Cancer, vol. 3, no. 10, pp. 721-732, 2003.

[57] Y. K. Choi, C. K. Kim, H. Lee et al., "Carbon monoxide promotes VEGF expression by increasing HIF- $1 \alpha$ protein level via two distinct mechanisms, translational activation and stabilization of HIF- $1 \alpha$ protein," Journal of Biological Chemistry, vol. 285, no. 42, pp. 32116-32125, 2010.

[58] D. J. Ceradini, A. R. Kulkarni, M. J. Callaghan et al., "Progenitor cell trafficking is regulated by hypoxic gradients through HIF-1 induction of SDF-1," Nature Medicine, vol. 10, no. 8, pp. 858-864, 2004.

[59] K. D. Poss and S. Tonegawa, "Heme oxygenase 1 is required for mammalian iron reutilization," Proceedings of the National Academy of Sciences of the United States of America, vol. 94, no. 20, pp. 10919-10924, 1997.

[60] J. Cisowski, A. Łoboda, A. Józkowicz, S. Chen, A. Agarwal, and J. Dulak, "Role of heme oxygenase-1 in hydrogen peroxide-induced VEGF synthesis: effect of HO-1 knockout," Biochemical and Biophysical Research Communications, vol. 326, no. 3, pp. 670-676, 2005.

[61] B. Bussolati, A. Ahmed, H. Pemberton et al., "Bifunctional role for VEGF-induced heme oxygenase-1 in vivo: induction of angiogenesis and inhibition of leukocytic infiltration," Blood, vol. 103, no. 3, pp. 761-766, 2004.

[62] A. Jözkowicz, I. Huk, A. Nigisch et al., "Heme oxygenase and angiogenic activity of endothelial cells: stimulation by carbon monoxide and inhibition by tin protoporphyrin-IX," Antioxidants and Redox Signaling, vol. 5, no. 2, pp. 155-162, 2003.

[63] H. H. Lin, Y. H. Chen, S. F. Yet, and L. Y. Chau, "After vascular injury, heme oxygenase-1/carbon monoxide enhances reendothelialization via promoting mobilization of circulating endothelial progenitor cells," Journal of Thrombosis and Haemostasis, vol. 7, no. 8, pp. 1401-1408, 2009.

[64] A. Nakao, D. J. Kaczorowski, B. S. Zuckerbraun et al., "Galantamine and carbon monoxide protect brain microvascular endothelial cells by heme oxygenase-1 induction," Biochemical and Biophysical Research Communications, vol. 367, no. 3, pp. 674-679, 2008.

[65] J. Dulak, R. Motterlini, A. Józkowicz et al., "Heme oxygenase activity modulates vascular endothelial growth factor synthesis in vascular smooth muscle cells," Antioxidants and Redox Signaling, vol. 4, no. 2, pp. 229-240, 2002.

[66] H. H. Marti and W. Risau, "Systemic hypoxia changes the organ-specific distribution of vascular endothelial growth factor and its receptors," Proceedings of the National Academy of Sciences of the United States of America, vol. 95, no. 26, pp. 15809-15814, 1998.

[67] R. K. Bruick and S. L. McKnight, "A conserved family of prolyl-4-hydroxylases that modify HIF," Science, vol. 294, no. 5545, pp. 1337-1340, 2001.

[68] M. Hirsilä, P. Koivunen, V. Günzler, K. I. Kivirikko, and J. Myllyharju, "Characterization of the human prolyl 4hydroxylases that modify the hypoxia-inducible factor," Journal of Biological Chemistry, vol. 278, no. 33, pp. 3077230780, 2003. 
[69] Y. Pan, K. D. Mansfield, C. C. Bertozzi et al., "Multiple factors affecting cellular redox status and energy metabolism modulate hypoxia-inducible factor prolyl hydroxylase activity in vivo and in vitro," Molecular and Cellular Biology, vol. 27, no. 3, pp. 912-925, 2007.

[70] D. F. Counts, G. J. Cardinale, and S. Udenfriend, "Prolyl hydroxylase half reaction: peptidyl prolyl-independent decarboxylation of $\alpha$-ketoglutarate," Proceedings of the National Academy of Sciences of the United States of America, vol. 75, no. 5, pp. 2145-2149, 1978.

[71] D. Gerald, E. Berra, Y. M. Frapart et al., "JunD reduces tumor angiogenesis by protecting cells from oxidative stress," Cell, vol. 118, no. 6, pp. 781-794, 2004.

[72] R. D. Guzy and P. T. Schumacker, "Oxygen sensing by mitochondria at complex III: the paradox of increased reactive oxygen species during hypoxia," Experimental Physiology, vol. 91, no. 5, pp. 807-819, 2006.

[73] E. L. Bell, T. A. Klimova, J. Eisenbart et al., "The Qo site of the mitochondrial complex III is required for the transduction of hypoxic signaling via reactive oxygen species production," Journal of Cell Biology, vol. 177, no. 6, pp. 1029-1036, 2007.

[74] N. S. Chandel, E. Maltepe, E. Goldwasser, C. E. Mathieu, M. C. Simon, and P. T. Schumacker, "Mitochondrial reactive oxygen species trigger hypoxia-induced transcription," Proceedings of the National Academy of Sciences of the United States of America, vol. 95, no. 20, pp. 11715-11720, 1998.

[75] A. Görlach, U. Berchner-Pfannschmidt, C. Wotzlaw et al., "Reactive oxygen species modulate HIF-I mediated PAI-I expression: involvement of the GTPase RacI," Thrombosis and Haemostasis, vol. 89, no. 5, pp. 926-935, 2003.

[76] J. S. Isaacs, Y. J. Jung, E. G. Mimnaugh, A. Martinez, F. Cuttitta, and L. M. Neckers, "Hsp90 regulates a von Hippel Lindau-independent hypoxia-inducible factor-1 alphadegradative pathway," Journal of Biological Chemistry, vol. 277, no. 33, pp. 29936-29944, 2002.

[77] S. H. Oh, J. K. Woo, Y. D. Yazici et al., "Structural basis for depletion of heat shock protein 90 client proteins by deguelin," Journal of the National Cancer Institute, vol. 99, no. 12, pp. 949-961, 2007.

[78] T. Hagen, C. T. Taylor, F. Lam, and S. Moncada, "Redistribution of intracellular Oxygen in hypoxia by Nitric Oxide: effect on HIF1 $\alpha$," Science, vol. 302, no. 5652, pp. 1975-1978, 2003.

[79] Y. Liu, H. Christou, T. Morita, E. Laughner, G. L. Semenza, and S. Kourembanas, "Carbon monoxide and nitric oxide suppress the hypoxic induction of vascular endothelial growth factor gene via the 5' enhancer," Journal of Biological Chemistry, vol. 273, no. 24, pp. 15257-15262, 1998.

[80] L. E. Huang, W. G. Willmore, J. Gu, M. A. Goldberg, and H. F. Bunn, "Inhibition of hypoxia-inducible factor 1 activation by carbon monoxide and nitric oxide: implications for oxygen sensing and signaling," Journal of Biological Chemistry, vol. 274, no. 13, pp. 9038-9044, 1999.

[81] B. Brüne and J. Zhou, "Nitric oxide and superoxide: interference with hypoxic signaling," Cardiovascular Research, vol. 75, no. 2, pp. 275-282, 2007.

[82] J. Deshane, S. Chen, S. Caballero et al., "Stromal cell-derived factor 1 promotes angiogenesis via a heme oxygenase 1dependent mechanism," Journal of Experimental Medicine, vol. 204, no. 3, pp. 605-618, 2007.

[83] K. I. Hiasa, M. Ishibashi, K. Ohtani et al., "Gene transfer of stromal cell-derived factor- $1 \alpha$ enhances ischemic vasculogenesis and angiogenesis via vascular endothelial growth factor/endothelial nitric oxide synthase-related pathway: next-generation chemokine therapy for therapeutic neovascularization," Circulation, vol. 109, no. 20, pp. 2454-2461, 2004.

[84] N. Urao, H. Inomata, M. Razvi et al., "Role of nox2based NADPH 0xidase in bone marrow and progenitor cell function involved in neovascularization induced by hindlimb ischemia," Circulation Research, vol. 103, no. 2, pp. 212-220, 2008.

[85] J. Zhang and C. A. Piantadosi, "Mitochondrial oxidative stress after carbon monoxide hypoxia in the rat brain," Journal of Clinical Investigation, vol. 90, no. 4, pp. 1193-1199, 1992.

[86] L. C. Cantley, "The phosphoinositide 3-kinase pathway," Science, vol. 296, no. 5573, pp. 1655-1657, 2002.

[87] C. A. Piantadosi and H. B. Suliman, "Mitochondrial transcription factor A induction by redox activation of nuclear respiratory factor 1," Journal of Biological Chemistry, vol. 281, no. 1, pp. 324-333, 2006.

[88] M. Meissner, M. Stein, C. Urbich et al., "PPAR $\alpha$ activators inhibit vascular endothelial growth factor receptor-2 expression by repressing Sp1-dependent DNA binding and transactivation," Circulation Research, vol. 94, no. 3, pp. 324332, 2004.

[89] L. Piqueras, A. R. Reynolds, K. M. Hodivala-Dilke et al., "Activation of PPAR $\beta / \delta$ induces endothelial cell proliferation and angiogenesis," Arteriosclerosis, Thrombosis, and Vascular Biology, vol. 27, no. 1, pp. 63-69, 2007.

[90] P. Fraisl, M. Mazzone, T. Schmidt, and P. Carmeliet, "Regulation of angiogenesis by Oxygen and metabolism," Developmental Cell, vol. 16, no. 2, pp. 167-179, 2009.

[91] K. Yamakawa, M. Hosoi, H. Koyama et al., "Peroxisome proliferator-activated receptor- $\gamma$ agonists increase vascular endothelial growth factor expression in human vascular smooth muscle cells," Biochemical and Biophysical Research Communications, vol. 271, no. 3, pp. 571-574, 2000.

[92] F. Biscetti, E. Gaetani, A. Flex et al., "Selective activation of peroxisome proliferator-activated receptor (PPAR) $\alpha$ and PPAR $\gamma$ induces neoangiogenesis through a vascular endothelial growth factor-dependent mechanism," Diabetes, vol. 57, no. 5, pp. 1394-1404, 2008.

[93] M. Okada, S. F. Yan, and D. J. Pinsky, "Peroxisome proliferator-activated receptor- $\gamma$ (PPAR- $\gamma$ ) activation suppresses ischemic induction of Egr-1 and its inflammatory gene targets," The FASEB Journal, vol. 16, no. 14, pp. 1861-1868, 2002.

[94] C. Jiang, A. T. Ting, and B. Seed, "PPAR- $\gamma$ agonists inhibit production of monocyte inflammatory cytokines," Nature, vol. 391, no. 6662, pp. 82-86, 1998.

[95] M. A. Simonin, K. Bordji, S. Boyault et al., "PPAR- $\gamma$ ligands modulate effects of LPS in stimulated rat synovial fibroblasts," American Journal of Physiology, vol. 282, no. 1, pp. C125-C133, 2002.

[96] I. Inoue, S. I. Goto, T. Matsunaga et al., "The ligands/activators for peroxisome proliferator-activated receptor $\alpha(\operatorname{PPAR} \alpha)$ and PPAR $\gamma$ increase $\mathrm{Cu} 2^{+}, \mathrm{Zn} 2^{+}$-superoxide dismutase and decrease p22phox message expressions in primary endothelial cells," Metabolism, vol. 50, no. 1, pp. 3$11,2001$.

[97] J. A. Polikandriotis, L. J. Mazzella, H. L. Rupnow, and C. M. Hart, "Peroxisome proliferator-activated receptor $\gamma$ ligands stimulate endothelial nitric oxide production through distinct peroxisome proliferator-activated receptor $\gamma$-dependent mechanisms," Arteriosclerosis, Thrombosis, and Vascular Biology, vol. 25, no. 9, pp. 1810-1816, 2005. 
[98] G. Krönke, A. Kadl, E. Ikonomu et al., "Expression of heme oxygenase-1 in human vascular cells is regulated by peroxisome proliferator-activated receptors," Arteriosclerosis, Thrombosis, and Vascular Biology, vol. 27, no. 6, pp. 12761282, 2007.

[99] N. Ouchi, R. Shibata, and K. Walsh, "AMP-activated protein kinase signaling stimulates VEGF expression and angiogenesis in skeletal muscle," Circulation Research, vol. 96, no. 8, pp. 838-846, 2005.

[100] J. F. Ndisang, N. Lane, and A. Jadhav, "Upregulation of the heme oxygenase system ameliorates postprandial and fasting hyperglycemia in type 2 diabetes," American Journal of Physiology, vol. 296, no. 5, pp. E1029-E1041, 2009.

[101] J. F. Ndisang and A. Jadhav, "Heme oxygenase system enhances insulin sensitivity and glucose metabolism in streptozotocin-induced diabetes," American Journal of Physiology, vol. 296, no. 4, pp. E829-E841, 2009.

[102] C. Cantó, Z. Gerhart-Hines, J. N. Feige et al., "AMPK regulates energy expenditure by modulating $\mathrm{NAD}^{+}$metabolism and SIRT1 activity," Nature, vol. 458, no. 7241, pp. 10561060, 2009.

[103] S. Papaiahgari, Q. Zhang, S. R. Kleeberger, H. Y. Cho, and S. P. Reddy, "Hyperoxia stimulates an Nrf2-ARE transcriptional response via ROS-EGFR-P13K-Akt/ERK MAP kinase signaling in pulmonary epithelial cells," Antioxidants and Redox Signaling, vol. 8, no. 1-2, pp. 43-52, 2006.

[104] S. H. Chang, J. Garcia, J. A. Melendez, M. S. Kilberg, and A. Agarwal, "Haem oxygenase 1 gene induction by glucose deprivation is mediated by reactive oxygen species via the mitochondrial electron-transport chain," Biochemical Journal, vol. 371, no. 3, pp. 877-885, 2003.

[105] Y. Higashi, K. Noma, M. Yoshizumi, and Y. Kihara, "Endothelial function and oxidative stress in cardiovascular diseases," Circulation Journal, vol. 73, no. 3, pp. 411-418, 2009.

[106] B. Wegiel, D. J. Gallo, K. G. Raman et al., "Nitric oxidedependent bone marrow progenitor mobilization by carbon monoxide enhances endothelial repair after vascular injury," Circulation, vol. 121, no. 4, pp. 537-548, 2010.

[107] B. Chen, L. Guo, C. Fan et al., "Carbon monoxide rescues heme oxygenase-1-deficient mice from arterial thrombosis in allogeneic aortic transplantation," American Journal of Pathology, vol. 175, no. 1, pp. 422-429, 2009.

[108] C. Chauveau, D. Bouchet, J. C. Roussel et al., "Gene transfer of heme oxygenase- 1 and carbon monoxide delivery inhibit chronic rejection," American Journal of Transplantation, vol. 2, no. 7, pp. 581-592, 2002.

[109] M. Schillinger, M. Exner, E. Minar et al., "Heme oxygenase1 genotype and restenosis after balloon angioplasty: a novel vascular protective factor," Journal of the American College of Cardiology, vol. 43, no. 6, pp. 950-957, 2004.

[110] R. Ullrich, M. Exner, M. Schillinger et al., "Microsatellite polymorphism in the heme oxygenase-1 gene promoter and cardiac allograft vasculopathy," Journal of Heart and Lung Transplantation, vol. 24, no. 10, pp. 1600-1605, 2005.

[111] L. E. Otterbein, B. S. Zuckerbraun, M. Haga et al., "Carbon monoxide suppresses arteriosclerotic lesions associated with chronic graft rejection and with balloon injury," Nature Medicine, vol. 9, no. 2, pp. 183-190, 2003.

[112] Y. M. Deng, B. J. Wu, P. K. Witting, and R. Stocker, "Probucol protects against smooth muscle cell proliferation by upregulating heme oxygenase-1," Circulation, vol. 110, no. 13, pp. 1855-1860, 2004.
[113] B. S. Zuckerbraun, Y. C. Beek, B. Wegiel et al., "Carbon monoxide reverses established pulmonary hypertension," Journal of Experimental Medicine, vol. 203, no. 9, pp. 21092119, 2006.

[114] M. P. Soares, M. P. Seldon, I. P. Gregoire et al., "Heme oxygenase-1 modulates the expression of adhesion molecules associated with endothelial cell activation," Journal of Immunology, vol. 172, no. 6, pp. 3553-3563, 2004.

[115] B. Sun, X. Zou, Y. Chen, P. Zhang, and G. Shi, "Preconditioning of carbon monoxide releasing molecule-derived CO attenuates LPS-induced activation of HUVEC," International Journal of Biological Sciences, vol. 4, no. 5, pp. 270-278, 2008.

[116] J. H. Kim, Y. K. Choi, K. S. Lee et al., "Functional dissection of Nrf2-dependent phase II genes in vascular inflammation and endotoxic injury using Keap1 siRNA," Free Radical Biology \& Medicine, vol. 53, no. 3, pp. 629-640, 2012.

[117] J. H. Kim, H. J. Na, C. K. Kim et al., "The nonprovitamin A carotenoid, lutein, inhibits NF- $\kappa$ B-dependent gene expression through redox-based regulation of the phosphatidylinositol 3-kinase/PTEN/Akt and NF- $\kappa \mathrm{B}$-inducing kinase pathways: role of $\mathrm{H}_{2} \mathrm{O}_{2}$ in NF- $\kappa \mathrm{B}$ activation," Free Radical Biology and Medicine, vol. 45, no. 6, pp. 885-896, 2008.

[118] G. Zhang and S. Ghosh, "Toll-like receptor-mediated NF- $\kappa$ B activation: a phylogenetically conserved paradigm in innate immunity," Journal of Clinical Investigation, vol. 107, no. 1, pp. 13-19, 2001.

[119] M. Jamaluddin, S. Wang, I. Boldogh, B. Tian, and A. R. Brasier, "TNF- $\alpha$-induced NF- $\kappa$ B/RelA Ser276 phosphorylation and enhanceosome formation is mediated by an ROSdependent PKAc pathway," Cellular Signalling, vol. 19, no. 7, pp. 1419-1433, 2007.

[120] M. Karin, "The beginning of the end: $\mathrm{I} \kappa \mathrm{B}$ kinase (IKK) and NF- $\kappa$ B activation,” Journal of Biological Chemistry, vol. 274, no. 39, pp. 27339-27342, 1999.

[121] X. M. Wang, H. P. Kim, K. Nakahira, S. W. Ryter, and A. M. K. Choi, "The heme oxygenase-1/carbon monoxide pathway suppresses TLR4 signaling by regulating the interaction of TLR4 with caveolin-1," Journal of Immunology, vol. 182, no. 6, pp. 3809-3818, 2009.

[122] G. Lee, H. J. Na, S. Namkoong et al., "4-O-methylgallic acid down-regulates endothelial adhesion molecule expression by inhibiting NF- $\kappa$ B-DNA-binding activity," European Journal of Pharmacology, vol. 551, no. 1-3, pp. 143-151, 2006.

[123] K. R. Wagner, F. R. Sharp, T. D. Ardizzone, A. Lu, and J. F. Clark, "Heme and iron metabolism: role in cerebral hemorrhage," Journal of Cerebral Blood Flow and Metabolism, vol. 23, no. 6, pp. 629-652, 2003.

[124] A. I. Alayash, R. P. Patel, and R. E. Cashon, "Redox reactions of hemoglobin and myoglobin: biological and toxicological implications," Antioxidants and Redox Signaling, vol. 3, no. 2, pp. 313-327, 2001.

[125] J. Wang, H. Zhuang, and S. Doré, "Heme oxygenase 2 is neuroprotective against intracerebral hemorrhage," Neurobiology of Disease, vol. 22, no. 3, pp. 473-476, 2006.

[126] J. Chen-Roetling and R. F. Regan, "Effect of heme oxygenase1 on the vulnerability of astrocytes and neurons to hemoglobin," Biochemical and Biophysical Research Communications, vol. 350, no. 1, pp. 233-237, 2006.

[127] J. Chen-Roetling, L. Benvenisti-Zarom, and R. F. Regan, "Cultured astrocytes from heme oxygenase-1 knockout mice are more vulnerable to heme-mediated oxidative injury," Journal of Neuroscience Research, vol. 82, no. 6, pp. 802-810, 2005. 
[128] L. Benvenisti-Zarom and R. F. Regan, "Astrocyte-specific heme oxygenase-1 hyperexpression attenuates hememediated oxidative injury," Neurobiology of Disease, vol. 26, no. 3, pp. 688-695, 2007.

[129] Y. Qu, J. Chen-Roetling, L. Benvenisti-Zarom, and R. F. Regan, "Attenuation of oxidative injury after induction of experimental intracerebral hemorrhage in heme oxygenase-2 knockout mice," Journal of Neurosurgery, vol. 106, no. 3, pp. 428-435, 2007.

[130] R. F. Regan, J. Chen, and L. Benvenisti-Zarom, "Heme oxygenase-2 gene deletion attenuates oxidative stress in neurons exposed to extracellular hemin," BMC Neuroscience, vol. 5, article 34, 2004.

[131] B. Rogers, V. Yakopson, Z. P. Teng, Y. Guo, and R. F. Regan, "Heme oxygenase-2 knockout neurons are less vulnerable to hemoglobin toxicity," Free Radical Biology and Medicine, vol. 35, no. 8, pp. 872-881, 2003.

[132] N. Panahian, M. Yoshiura, and M. D. Maines, "Overexpression of heme oxygenase-1 is neuroprotective in a model of permanent middle cerebral artery occlusion in transgenic mice," Journal of Neurochemistry, vol. 72, no. 3, pp. 11871203, 1999.

[133] A. S. Ahmad, H. Zhuang, and S. Doré, "Heme oxygenase-1 protects brain from acute excitotoxicity," Neuroscience, vol. 141, no. 4, pp. 1703-1708, 2006.

[134] K. Chen, K. Gunter, and M. D. Maines, "Neurons overexpressing heme oxygenase- 1 resist oxidative stress-mediated cell death," Journal of Neurochemistry, vol. 75, no. 1, pp. 304$313,2000$.

[135] H. Parfenova, S. Basuroy, S. Bhattacharya et al., "Glutamate induces oxidative stress and apoptosis in cerebral vascular endothelial cells: contributions of $\mathrm{HO}-1$ and $\mathrm{HO}-2$ to cytoprotection," American Journal of Physiology, vol. 290, no. 5, pp. C1399-C1410, 2006.

[136] G. Scapagnini, V. D’Agata, V. Calabrese et al., "Gene expression profiles of heme oxygenase isoforms in the rat brain," Brain Research, vol. 954, no. 1, pp. 51-59, 2002.

[137] E. F. Chang, R. J. Wong, H. J. Vreman et al., "Heme oxygenase-2 protects against lipid peroxidation-mediated cell loss and impaired motor recovery after traumatic brain injury," Journal of Neuroscience, vol. 23, no. 9, pp. 3689-3696, 2003.

[138] J. Wang and S. Doré, "Heme oxygenase 2 deficiency increases brain swelling and inflammation after intracerebral hemorrhage," Neuroscience, vol. 155, no. 4, pp. 1133-1141, 2008.

[139] C. W. Nelson, E. P. Wei, J. T. Povlishock, H. A. Kontos, and M. A. Moskowitz, "Oxygen radicals in cerebral ischemia," American Journal of Physiology, vol. 263, no. 5, part 2, pp. H1356-H1362, 1992.

[140] Y. Gürsoy-Özdemir, A. Can, and T. Dalkara, "Reperfusioninduced oxidative/nitrativie injury to neurovascular unit after focal cerebral ischemia," Stroke, vol. 35, no. 6, pp. 14491453, 2004.

[141] V. Calabrese, A. M. Giuffrida Stella, D. A. Butterfield, and G. Scapagnini, "Redox regulation in neurodegeneration and longevity: role of the heme oxygenase and HSP70 systems in brain stress tolerance," Antioxidants and Redox Signaling, vol. 6, no. 5, pp. 895-913, 2004.

[142] H. P. Kim, X. Wang, J. Zhang et al., "Heat shock protein70 mediates the cytoprotective effect of carbon monoxide: involvement of $\mathrm{p} 38 \beta$ MAPK and heat shock factor-1," Journal of Immunology, vol. 175, no. 4, pp. 2622-2629, 2005.

[143] J. Biermann, W. A. Lagrèze, C. Dimitriu, C. Stoykow, and U. Goebel, "Preconditioning with inhalative carbon monoxide protects rat retinal ganglion cells from ischemia/reperfusion injury," Investigative Ophthalmology and Visual Science, vol. 51, no. 7, pp. 3784-3791, 2010.

[144] X. Zhang, P. Shan, J. Alam, R. J. Davis, R. A. Flavell, and P. J. Lee, "Carbon monoxide modulates Fas/Fas ligand, caspases, and $\mathrm{Bcl}-2$ family proteins via the p38 $\alpha$ mitogen-activated protein kinase pathway during ischemia-reperfusion lung injury," Journal of Biological Chemistry, vol. 278, no. 24, pp. 22061-22070, 2003.

[145] S. S. Almeida, C. S. Queiroga, M. F. Sousa, P. M. Alves, and H. L. Vieira. Paraaaa, "Carbon monoxide modulates apoptosis by reinforcing oxidative metabolism in astrocytes: role of BCL-2," Journal of Biological Chemistry, vol. 287, no. 14, pp. 10761-10770, 2012.

[146] A. B. Stein, R. Bolli, B. Dawn et al., "Carbon monoxide induces a late preconditioning-mimetic cardioprotective and antiapoptotic milieu in the myocardium," Journal of Molecular and Cellular Cardiology, vol. 52, no. 1, pp. 228-236, 2012.

[147] I. Bauer and B. H. Pannen, "Bench-to-bedside review: carbon monoxide-from mitochondrial poisoning to therapeutic use," Critical Care, vol. 13, no. 4, p. 220, 2009.

[148] R. Motterlini, J. E. Clark, R. Foresti, P. Sarathchandra, B. E. Mann, and C. J. Green, "Carbon monoxide-releasing molecules: characterization of biochemical and vascular activities," Circulation Research, vol. 90, no. 2, pp. E17-E24, 2002.

[149] R. Motterlini, B. E. Mann, T. R. Johnson, J. E. Clark, R. Foresti, and C. J. Green, "Bioactivity and pharmacological actions of carbon monoxide-releasing molecules," Current Pharmaceutical Design, vol. 9, no. 30, pp. 2525-2539, 2003.

[150] J. E. Clark, P. Naughton, S. Shurey et al., "Cardioprotective actions by a water-soluble carbon monoxide-releasing molecule," Circulation Research, vol. 93, no. 2, pp. e2-e8, 2003. 


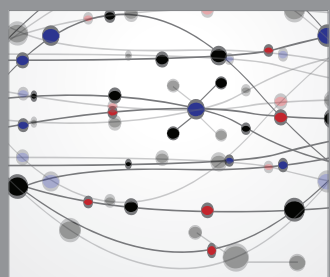

The Scientific World Journal
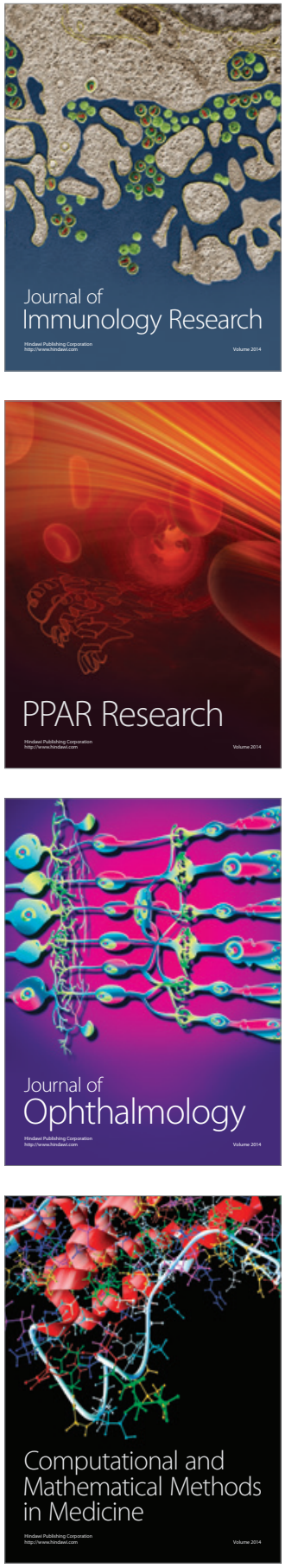

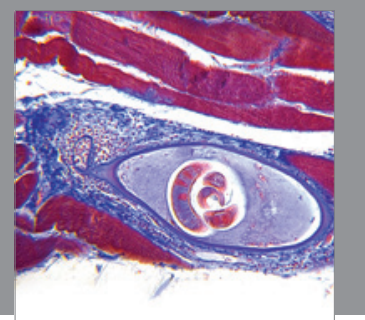

Gastroenterology

Research and Practice
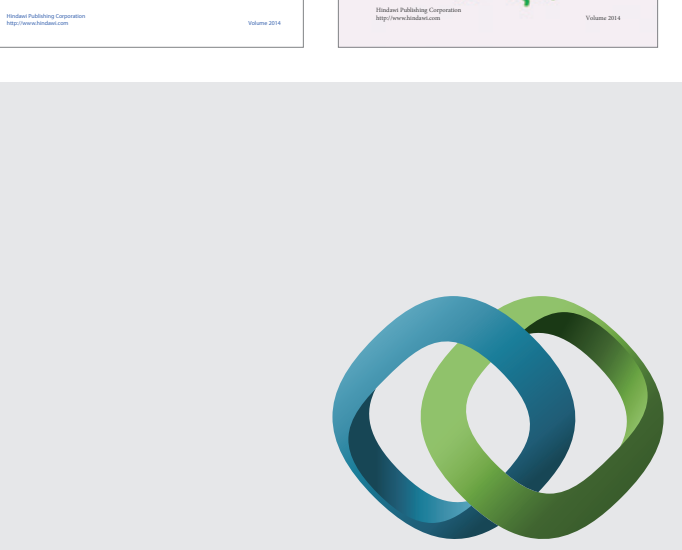

\section{Hindawi}

Submit your manuscripts at

http://www.hindawi.com
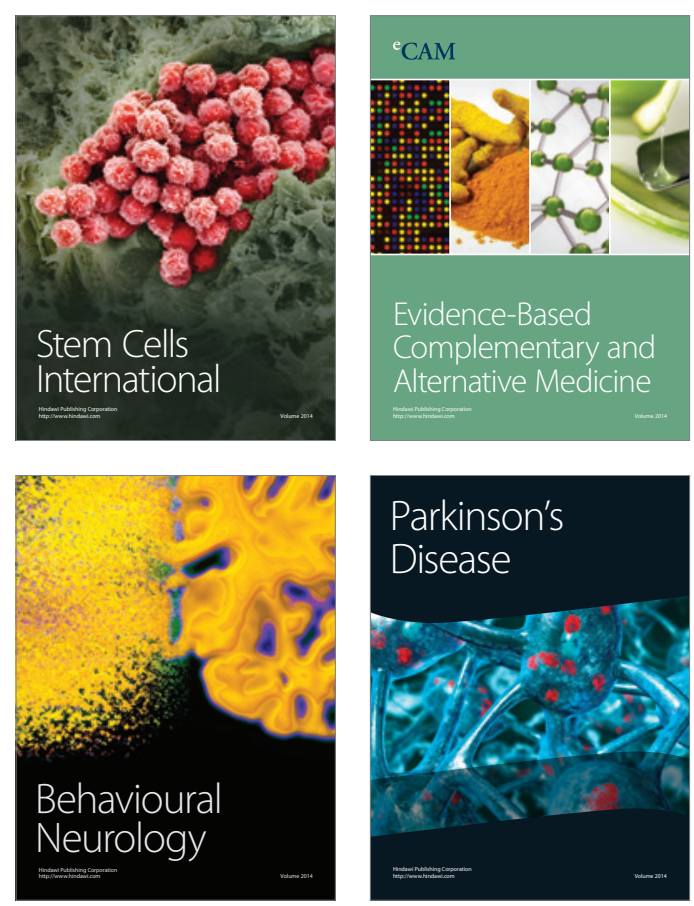

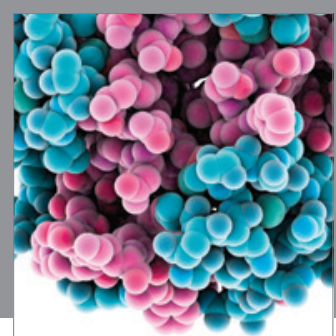

Journal of
Diabetes Research

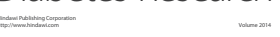

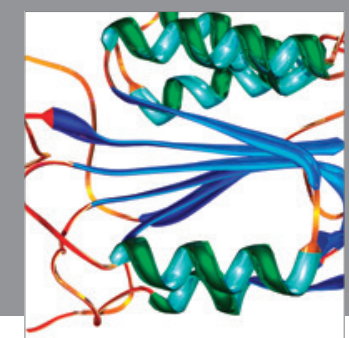

Disease Markers
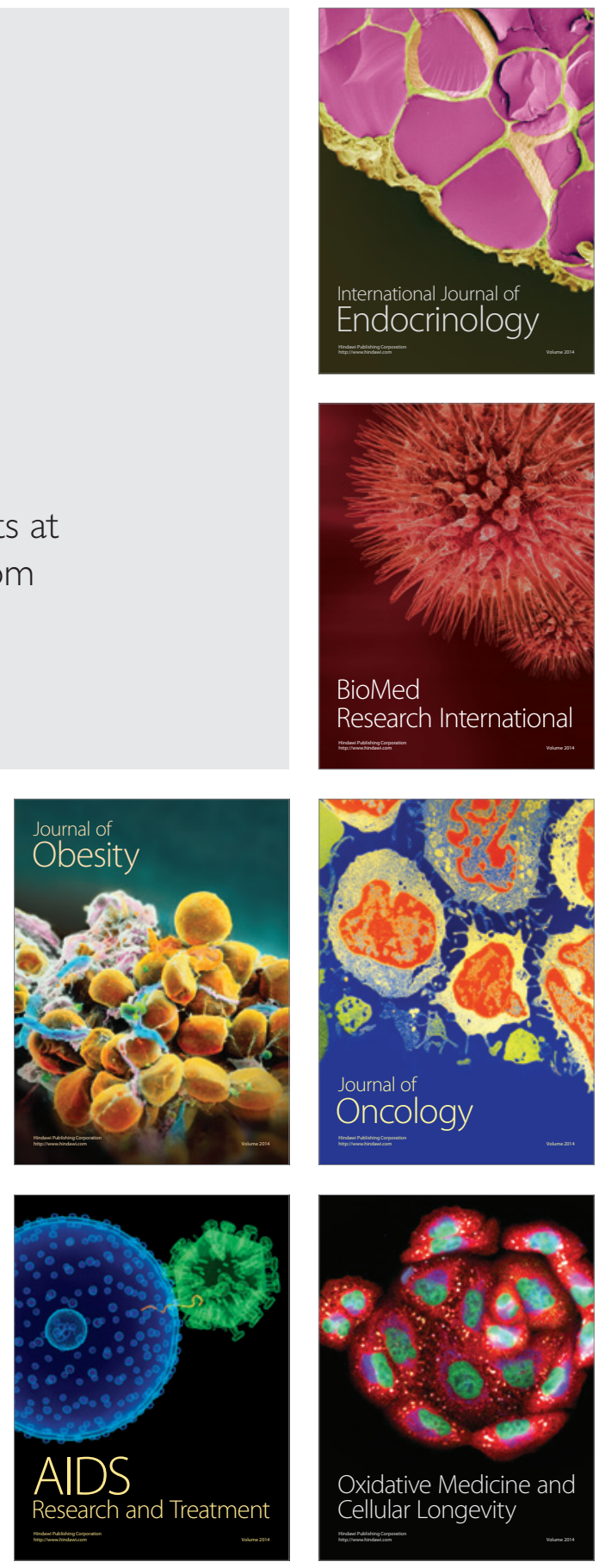